\title{
El capitalismo del holding transnacional en el sector forestal chileno: la consolidación de una hegemonía territorial
}

\author{
The capitalism of the transnational holding companies in Chile's forestry sector: \\ consolidation of a territorial hegemony
}

\author{
Massimiliano Farris* Óscar Martínez Royo**
}

\begin{abstract}
Resumen: El sector forestal ha determinado la construcción del territorio en el centro-sur de Chile. Para estudiar dicha construcción, se ha utilizado como clave analítica el concepto de hegemonía y su aplicación territorial. La metodología aborda la hegemonía territorial según tres dimensiones: histórico-política, económico-empresarial y simbólico-cultural. Se concluye que se ha consolidado una territorialidad hegemónica, caracterizada por el monocultivo y cuyas bases históricas están en prácticas políticas que han favorecido un oligopolio de holdings transnacionales.
\end{abstract}

Palabras clave: hegemonía territorial, plantaciones forestales industriales, monocultivo, holdings transnacionales, Biobío, Chile

\begin{abstract}
The forestry sector has determined the construction of the territory in the center-southern area of Chile. In order to understand such construction, the concept of hegemony, as well as its territorial realm have been used as analytical tools. The methodology considers territorial hegemony according to three dimensions: historical-political, economicbusiness and symbolic-cultural. It concluded that a hegemonic territoriality has been consolidated, and it is characterized by monoculture that is historically based on political practices that have favoured an oligopoly of transnational holdings.
\end{abstract}

Keywords: territorial hegemony, industrial forestry plantations, monoculture, transnational holding companies, Biobío region, Chile.

Recibido: 5 marzo 2018 Aceptado: 5 junio 2018

\footnotetext{
Italiano, autor principal. Doctor en Geografía, especialista en geografía política y desarrollo rural, Postdoctorante, Profesor invitado Departamento de Geografía de la Universidad de Chile. Este trabajo se enmarca dentro de los siguientes proyectos de investigación: Postdoctorado FONDECYT n 3160767 “Territorio y Sustentabilidad en el discurso del "desarrollo" en contextos rurales. Análisis y perspectivas comparadas entre Chile y España”, duración 3 años - y PIA CONICYT 1404 "Dinámicas naturales, espaciales y socio-culturales: perspectivas sobre los conflictos socio-ambientales en territorios forestales de Chile, 1975-2014" - duración 4 años, massimilianof@,uchilefau.cl

** Chileno, Autor secundario. Licenciado en Ciencias Políticas, interesado en el tema de la sustentabilidad socioambiental desde la Filosofía política, oscarnicolas.martinez@,mail.udp.cl
} 


\section{Introducción}

En Chile, la dimensión territorial en el discurso del "desarrollo" se ha concretado en la idea del "desarrollo regional". Ésta hace hincapié en sacar los territorios más pobres de la marginalidad, superando las desigualdades regionales ${ }^{2}$. Para ello se han fomentado políticas económicas de "laissaiz-faire" enfocadas en el crecimiento económico a partir de especificidades locales/regionales que fomenten el aprovechamiento de las ventajas comparativas, principalmente basadas en la extracción de recursos naturales. De esta forma, se ha ido consolidando una economía de "cluster" sustentada en el aprovechamiento de las condiciones favorables y la vocación productiva de un territorio para determinadas actividades (cluster minero, forestal, agrario, de la piscicultura etc.). Complementariamente, el desarrollo rural ${ }^{3}$ se puede considerar como una especificación de este enfoque regional y resulta condicionado por el crecimiento económico de las (grandes) empresas agroindustriales, orientadas principalmente a la exportación ${ }^{4}$. El caso de las plantaciones forestales es representativo de esta construcción del territorio como clúster productivo.

El sector forestal se presenta como un oligopolio, con pocas grandes empresas que concentran la mayoría de la superficie plantada y de los medios de transformación, y se ha sustentado por la expansión de un monocultivo (de Pinus radiata y eucalipto, principalmente) que ha modificado en profundidad los territorios de las comunas de la Cordillera de la Costa, entre el $34^{\circ}$ y el $38^{\circ}$ paralelo sur, gracias a las ayudas económicas estatales aprobadas en dictadura.

El área de expansión del sector forestal ha coincidido (en términos generales) con el área considerada afectada por algún grado de erosión del suelo ${ }^{5}$. Junto a esto, es preciso señalar que las comunas que concentran la mayor superficie forestada y las plantas industriales de transformación se ubican entre las que han marcado los valores más bajos del Índice de Desarrollo Humano ${ }^{6}$. Estas características siguen siendo las principales justificaciones que tienen los actores forestales para validar su actuar: por una parte, la forestación habría tenido un impacto positivo en consolidar los suelos y frenar la erosión, mientras desde un punto de vista social ha mejorado las condiciones de vida de la población generando puestos de trabajo

\footnotetext{
${ }^{1}$ Arenas, F. (1999). Organización territorial y desarrollo regional en Chile. Estudios Geográficos, 60 (23):101-119. Arenas, F. (2009). El Chile de las regiones: una historia inconclusa. Estudios Geográficos, 70 (266): 11-39.

2 Aroca, P. (2009). Desigualdades regionales en Chile. Foreign Affairs Latinoamérica, 9 (1): 53-63

3 Pezo, L. (2007). Construcción del desarrollo rural en Chile: apuntes para abordar el tema desde una perspectiva de la sociedad civil. Revista Mad, 17, 90-112

${ }^{4}$ Canales, M., \& Hernández, M. C. (2011). Del fundo al mundo. Cachapoal, un caso de globalización agropolitana. Espacio Abierto, 20(4); De Matheus e Silva, L. (2016). Desposeer para acumular: reflexiones sobre las contradicciones del proceso de modernización neoliberal de la agricultura chilena. Mundo Agrario, 17:34. Universidad de la Plata, Argentina; Hernández, R. y Pezo, L. (2010). La Ruralidad Chilena Actual. Aproximaciones desde la Antropología. Colibris, Santiago, Chile

5 CIREN (2010) Determinacion de la erosion actual y potencial de los suelos de Chile http://www.corma.cl/_file/material/determinacion-de-la-erosion-actual-y-potencial-de-los-suelos-de-chile-ciren2010.pdf

6 PNUD (2004) Las trayectorias del desarrollo humano en las comunas de Chile (1993- 2003) http://desarrollohumano.cl/idh/download/IDHC\%20con\%20portada.pdf
} 
en territorios deprimidos ${ }^{7}$. Sin embargo, existen varios elementos que ponen en duda esta visión corporativa. Un estudio de la variación de la pobreza en las comunas forestales ${ }^{8}$ evidencia que, si bien ésta ha disminuido en los últimos decenios este es un fenómeno que se ha dado a escala país. Por otra parte, se sigue manteniendo la brecha con el promedio regional como estatal, por tanto, no hay evidencia del aporte directo del sector forestal a esta mejora. También es importante señalar que en el año 2014 se creó un programa especial para "Zonas rezagadas" : de las 6 zonas de intervención, 5 están en el área en la cual se concentra el monocultivo forestal. En términos de contribución al empleo, en la principal región forestal ${ }^{10}$, el Biobio, los ocupados directos en las diferentes fases de la producción (desde la plantación a la industria secundaria) concentran no más del $4 \%$ del total regional ${ }^{11}$.

Junto a lo anterior, la expansión de este monocultivo ha generado serios cuestionamientos al modelo también de tipo medio ambiental: se le atribuyen una serie de externalidades negativas como la reducción de la biodiversidad, la contaminación y empobrecimiento de los suelos ${ }^{12}$, la disminución de la disponibilidad de agua, el aumento de los incendios. Es significativo evidenciar que de parte de las empresas - y también de varios sectores institucionales y del mundo académico - estos dos últimos problemas se deben principalmente al "cambio climático" y lo que se espera es que se implementen acciones de adaptación, sin poner en duda el modelo productivo actual ${ }^{13}$. El dato incontrovertible es que en la mayoría de las comunas forestales el abastecimiento de agua potable ${ }^{14}$ se da a través de camiones aljibe y que la población constata la desaparición de las napas subterráneas; mientras que los incendios están evidenciando una mayor virulencia con una gran superficie involucrada.

En razón de estos cuestionamientos, este trabajo plantea una interpretación desde la hegemonía territorial de las razones políticas, económicas y sociales que han permitido que el sector se pudiera expandir de tal modo, considerando en particular los territorios donde no existen comunidades indígenas.

7 CORMA Evaluación del aporte económico y social del sector forestal. http://www.corma.cl/bibliotecadigital/publicaciones-y-estudios

${ }^{8}$ Ver las Figuras 5 y 6 a la página 24. PROGEA (2015) Aporte económico y social del sector forestal en Chile y análisis de encadenamiento.http://www.corma.cl/_file/material/aporte-economico-y-social-del-sector-forestal-en-chile-y-

analisis-de-encadenamiento.pdf

${ }_{9}$ Territorios que tienen una brecha de pobreza tanto con el nivel estatal como el regional y con significativos problemas de aislamiento. En: http:/ /www.zonasrezagadas.subdere.gov.cl/

10 Innovar Chile (2016) Estudio fuerza laboral de la industria forestal Chilena 2015-2030. http://www.corma.cl/_file/material/estudio-fuerza-laboral-de-la-industria-forestal-chilena-2015-2030.pdf

11 Para el año 2016, los ocupados en las diferentes ramas del sector alcanzaban el total de 42.701 en la región del Biobio. INFOR (2016) Anuario forestal 2017, 161.

${ }^{12}$ Montalba, R. y Carrasco, N. (2003). Modelo forestal chileno y conflicto mapuche: ¿ecologismo cultural? Ecología Politica, 26, 63-69

13 CORMA (2015) El agua y las plantaciones forestales. Aporte al conocimiento de la gestión sustentable; CORMA (2016) Las Plantaciones Forestales. Un Aporte a la Recuperación de Suelos Degradados en Chile

En: http://www.corma.cl/biblioteca-digital/publicaciones-y-estudios

${ }^{14}$ Asociación Municipalidades BioBio (2015) Impacto de las operaciones forestales en la región del Biobio desde la perspectiva municipal y su vinculación al riesgo de desastres y emergencias. Resumen Ejecutivo. 


\section{Marco teórico}

\section{Territorialidades rurales y recursos naturales en disputa, entre competitividad global y hegemonía territorial}

En estudios previos sobre la implementación de estrategias de desarrollo local ${ }^{15}$ se ha mostrado que los territorios rurales son sistemas complejos, en los cuales se concentra una amplia variedad de "bienes territoriales" ${ }^{16}$ y se interconecta una pluralidad de actividades (económicas, políticas y culturales) y actores, cuyos intereses a menudo son contradictorios o conflictivos. Esta pluralidad de actividades se refleja en un tejido de redes de actores ${ }^{17}$ que a su vez implica una pluralidad de relaciones que se proyectan transescalarmente en el espacio ${ }^{18}$. Desde una perspectiva escalar, Gorenstein ${ }^{19}$ evidencia como en América Latina, la explotación de los recursos naturales muestra un tránsito desde los "complejos productivos", a escala estatal y regional, a los "complejos o cadenas globales", donde la dotación de recursos naturales renueva las formas de los anclajes espaciales del capitalismo ${ }^{20}$, con actores que operan simultáneamente en diversas escalas. A la vez, implican una transformación territorial que desencadena disputas por el uso de los distintos recursos territoriales ${ }^{21}$ y conflictos socioambientales en los cuales se contraponen distintos lenguajes de valoración sobre el territorio $^{22}$. Estos lenguajes distintos reflejan formas diferentes de plantear la relación entre sociedad humana y territorio, no necesariamente en la perspectiva de la explotación sino más bien de un "cuidado del territorio" como plantea Magnaghi ${ }^{23}$. Governa ${ }^{24}$, a su vez, ha

${ }^{15}$ Farris, (2013). Desarrollo rural en tiempos de globalización. Análisis de las políticas públicas en su aplicación a estudio de casos (España e Italia). Tesis de Doctorado defendida el 19/04/2013 por la Universidad Complutense Madrid; Farris, M. (2012). Valorización del patrimonio endógeno rural:" buenas prácticas" del GAL Terre Shardana (Italia). En Investigando en rural, 605-614, Ed. Ulzama; Molina Ibáñez, M. y Farris, M. (2012). Desarrollo rural y políticas públicas: un análisis multiescalar. Geographicalia 59-60. Zaragoza, España; Molina Ibáñez, M. (2005). Hacia un equilibrio territorial en la España del siglo XXI: los retos del desarrollo rural. Cuenta y razón del pensamiento actual, 91-106. Fundación de Estudios Sociológicos, Madrid, España

${ }^{16}$ Dematteis y Governa, (2005) Territorialità, Sviluppo Locale, Sostenibilità: il modelo SLoT. Franco Angeli

17 Peck, J. (2010). Economías políticas de la escala: políticas rápidas, relaciones inter escalares y workfare neoliberal. En: Fernández, V. y Brandao, R. Escalas y Políticas del desarrollo regional. Desafíos para América Latina. Miño y Davila, Buenos Aires, Argentina

${ }_{18}$ Gutierrez Puebla, J. (2001). Escalas espaciales, escalas temporales. Estudios geográficos, 62:242, 89-104, Madrid, España; Farris, M. (2008). Relaciones multi-escalares, políticas públicas y desarrollo local rural. Un acercamiento teórico desde una perspectiva mediterránea. Actas XI Coloquio Ibérico de Geografía. (ISBN: 978-84-8138-792-6), Alcalá de Henares, España

19 Gorenstein, S. (2015). Transformaciones territoriales contemporáneas. Desafíos del pensamiento latinoamericano. EURE, 41:122, Santiago, Chile.

${ }^{20}$ González, S. (2005). La geografía escalar del capitalismo actual. Geo Crítica / Scripta Nova. Revista electrónica de geografía y ciencias sociales IX: 189. Universidad de Barcelona, Barcelona, España.

${ }^{21}$ Folchi, M. (2001). Conflictos de contenido ambiental y ecologismo de los pobres: no siempre pobres, ni siempre ecologistas. Ecología Política, 22

22 Martínez-Alier, J. (2004). El ecologismo de los pobres. Conflictos ambientales y lenguaje de valoración. Icaria, Barcelona, España.

${ }^{23}$ Magnaghi, A. (2000). Il progetto locale. Bollati Boringhieri, Milano, Italia

${ }^{24}$ Governa, F. (2007). Territorialità e azione collettiva. Una riflessione critica sulle teorie e le pratiche di sviluppo locale. Rivista Geografica Italiana, 114, 335-361, Roma, Italia 
evidenciado cómo la construcción de los territorios se puede reconducir en términos generales a dos modelos de territorialidad: una "pasiva" y otra "activa". Cada territorio se va conformando en función de que una de estas dos resulta predominante sobre la otra, a raíz de las relaciones de poder que se establecen entre los distintos actores territoriales, en los diferentes momentos históricos. La primera tipología enfatiza el papel que juegan los sujetos que ejercen el poder (económico o político) en poner en marcha acciones de transformación territorial, a menudo persiguiendo estrategias de control que tienden a la exclusión social y a la gestión elitista de los recursos. La otra, hace hincapié en la práctica social colectiva y compartida de los sujetos locales y aborda la cuestión del reparto efectivo de las competencias entre gobierno central y actores locales. Una "territorialidad activa", por lo tanto, se desprende de estrategias de inclusión orientadas a promover las especificidades locales en base a la confrontación de necesidades e intereses de todos los actores implicados. Estas estrategias implican la implementación de políticas "de abajo hacia arriba" para facilitar un progresivo alejamiento del centro de gravedad de la toma de decisiones hacia los niveles inferiores, con la consecuente acogida de las voluntades locales en las escalas supra-locales.

Las consideraciones anteriores, evidencian que el territorio es una construcción social dada por las relaciones de poder entre diferentes actores territoriales y éstas son determinantes en la definición del uso de los recursos naturales, tal como se muestra en el caso estudiado en este artículo. En relación a esto, es fundamental profundizar sobre el concepto de hegemonía y su aplicación a la dimensión territorial. Sevilla ${ }^{25}$, mediante una historia de la planificación espacial, propone comprender el surgimiento de determinados discursos, prácticas y técnicas de gobierno, a un nivel espacial y de su influencia sobre las personas insertas en dicha planificación. Para este autor la territorialidad es "una estrategia en la que un sujeto o grupo social traza su proyecto de influencia y dominio sobre otros grupos de población por medios indirectos, a través de una mediación que instrumentaliza el espacio para dichos fines”26. El espacio, como categoría de análisis, es aprehendido desde lo político y utiliza el concepto de hegemonía como "hegemonía territorial", entendida como "la práctica de diseminación de formas de uso y concepción del espacio -de códigos que territorializan ese espaciocompatibles con el proyecto de orden socioespacial del bloque dominante" 27 .

Así Sevilla reconstruye los elementos que caracterizan la visión gramsciana de hegemonía, que consta de 5 puntos:

1. Aparece como "un principio de dirección en toda una serie de ámbitos (económico, intelectual, moral, etc.) que permite a un determinado bloque social guiar la sociedad a través del consenso y sin imposiciones violentas, lo que garantiza un orden político estable y duradero" 28 .

2. Es difusa y atraviesa el conjunto del tejido social, afectando la esfera privada.

3. "Toda relación de hegemonía es necesariamente una relación pedagógica"29

\footnotetext{
${ }^{25}$ Sevilla, Á. (2014). Hegemonía, gubernamentalidad, territorio. Apuntes metodológicos para una historia social de la planificación. Empiria, 27, 49-72

${ }^{26}$ Ibid. 63

${ }^{27}$ Idem.

${ }^{28}$ Ibid. 54

${ }^{29}$ Ibid, 55
} 
4. "Transmite una concepción del mundo que se integra en las conciencias como sentido común y se traslada al nivel de lo vivido en las prácticas materiales y el lenguaje"30.

5. Su propósito final es legitimar "un determinado proyecto de orden social, facilitando la labor del gobierno mediante la producción de consenso y reduciendo por tanto la necesidad de coerción y uso de la fuerza" ${ }^{31}$. Es decir, se anticipa al conflicto social abierto. En esta perspectiva, la hegemonía territorial implica un trabajo sistemático de desactivación de posibles conflictos sociales territorializados, a través de prácticas blandas realizadas de forma directa o indirecta por el grupo social hegemónico que le permiten consolidarse como un actor imprescindible en el territorio, tanto en los aspectos económicos (por ejemplo, como el que garantiza el trabajo), sociales (a través de la financiación de actividades lúdicas/deportivas; gestión y/o donaciones a escuelas, organizaciones sociales etc.) y políticas (financiación directa o indirecta de campañas electorales).

De manera complementaria, Sevilla, reelaborando la propuesta de Foucault ${ }^{32}$, plantea una gubernamentalidad territorial como "la racionalidad de gobierno que, apoyándose en un conjunto de técnicas y saberes orgánicos, implementan usos y concepciones, bien desde una perspectiva policial (conocer, controlar y disciplinar las territorialidades de la población) o liberal (propiciar, favorecer e incentivar ciertas territorialidades)" ${ }^{\prime 33}$. En este caso se refiere a prácticas represivas directas (allanamientos, encarcelamientos, violencia policial etc.) e indirectas (leyes especiales para un territorio o un grupo social que habita un territorio, normas de producción que influyen en determinadas prácticas productivas territoriales, fomento empresarial etc.).

La territorialidad, entonces, se construye mediante distintas prácticas que reflejan la necesidad de la clase dominante de orientar las clases subalternas en una construcción del espacio funcional a sus intereses. En esta perspectiva, el espacio también poseería una capacidad performativa o pedagógica.

En los siguientes apartados, evidenciamos cómo, en los territorios forestales de Chile, destacando en particular el caso de la región del Biobío, se ha articulado una territorialidad hegemónica, funcional a los intereses de unos pocos grandes holdings transnacionales.

\section{Metodología}

El objetivo del trabajo ha sido comprobar si el concepto de hegemonía territorial puede ser aplicable al caso del sector forestal en Chile. Para ello se han considerado tres dimensiones:

- la dimensión histórico-política, es decir los procesos políticos e ideológicos que han determinado la consolidación de determinadas redes sociales y orientado una gestión técnico-científica del sector forestal;

\footnotetext{
30 Idem

${ }^{31}$ Idem

32 Foucault, M. (2008). Seguridad, territorio, población. Madrid: Akal.

33 Sevilla, ob. cit., 64
} 
- la dimensión económico-empresarial que tiene que ver con la estructura de las empresas del sector que se han constituido en un oligopolio y ha plasmado el territorio a través del sistema productivo del monocultivo;

- la dimensión simbólico-cultural tiene que ver con esas expresiones de la hegemonía en las prácticas cotidianas que permiten la construcción de imaginarios territoriales funcionales a los actores hegemónicos.

En función de lo anterior se ha realizado un trabajo de revisión y sistematización bibliográfica, considerando diferentes fuentes: investigaciones académicas relativas al territorio - de tipo sociológico, del mercado del trabajo, de las diferentes actividades económicas y de la forestal en particular; estudios sobre la estructura del capitalismo chileno, en particular de las sociedades con intereses en el sector forestal; estudios sectoriales de Instituciones gubernamentales; artículos periodísticos relacionados directamente con el sector forestal. Esto ha permitido reconstruir las primeras dos dimensiones. Junto a eso, durante los años 2016 y 2017 se realizó un trabajo etnográfico a través de 10 visitas a terreno para conocer y comprender las diferentes realidades territoriales de la región del Biobío, efectuando entrevistas -a representantes forestales, vitivinicultores, agricultores, técnicos agrarios, administradores públicos- y observaciones de campo respaldadas en fotografías y videos, lo cual ha permitido constituir un archivo que posibilita evidenciar con mayor claridad la dimensión simbólicocultural.

\section{Desarrollo}

\section{Las bases histórico-políticas de la hegemonía territorial: la evolución de la legislación sobre el sector forestal como expresión de una tecnocracia}

El análisis de la evolución de la legislación forestal evidencia el rol que han tenido, tal como se evidencia a continuación, importantes científicos y técnicos: Gay y Albert, la CORFO y los "tecnopols" han sido los instrumentos de los diferentes gobiernos para imponer la implantación de especies forestales exógenas y desarrollar la industria maderera. Retomando los planteamientos de Sevilla, la legislación forestal se puede considerar como herramienta para una planificación territorial orientada por la gubernamentalidad. Expresión mayor de esta política de transformación territorial ha sido el Decreto Ley 701 del 1974, promulgado durante la dictadura del general Pinochet. Esta visión evidencia una territorialidad "pasiva" (en el sentido que le otorga Governa) en la cual los agentes locales, los habitantes de los territorios objeto de planificación, no son involucrados en la toma de decisiones. Quienes se encargan de representar el interés superior colectivo son los diferentes "técnicos", nombrados por el mundo político aun cuando resguardan los intereses de la clase económica hegemónica.

En la historia chilena se pueden identificar gestiones o intentos por implementar legislación de tipo forestal desde el año 1830. Cabeza ${ }^{34}$, indica que los sectores que en un

\footnotetext{
${ }^{34}$ Cabeza, A. (1988). Aspectos históricos de la legislación forestal vinculada a la conservación; la evolución de las Áreas Silvestres Protegidas de la zona de Villarrica y la creación del primer parque nacional de Chile. Documento de Trabajo No101. CONAF, Santiago, Chile.
} 
comienzo se muestran favorables o contrarios a este hecho, se organizan en torno a dos actividades productivas. Por una parte, estarían los intereses del sector agrícola organizados en torno a la Sociedad Nacional de Agricultura; por otro lado, está el sector minero. Los primeros defendían la idea de legislar en esta materia, con el fin de regular un uso y explotación racional de los bosques. Los segundos argüían que este tipo de legislaciones generaría trabas al desarrollo minero y, por tanto, al país vía reducción de ingresos por imposiciones ${ }^{35}$, en un escenario en que la ventaja comparativa de los productores guiaba las políticas económicas ${ }^{36}$. A causa de la evidente erosión de los suelos de Chile y un contexto internacional que comienza a preocuparse de estos asuntos, se empiezan a levantar voces de alarma que invitan a legislar y reglamentar el uso de los bosques. Primeramente, en los años treinta de siglo XIX personajes como Claudio Gay hacen referencia a la magnitud de la catástrofe ejercida sobre el territorio por la quema de bosques con fines agrícolas y ganaderos.

Históricamente, en el mundo rural se ha asentado el convencimiento cultural de una beneficiosa función del fuego para las prácticas agrarias: por una parte, se valoraba su utilidad para "limpiar" los terrenos de los arboles y abrir espacios a los cultivos y, por otra parte, se consideraba que la ceniza que quedaba después del incendio fertilizaba el suelo. Aunque en los primeros años después de la quema, la producción era altamente provechosa, luego resultaba evidente que la productividad mermaba notablemente y se extendían los terrenos secanos ${ }^{37}$. Asimismo, había problemas de desertificación en el centro de Chile, asociados a la no regulación de la actividad maderera ${ }^{38}$.

Se podría decir que, a principios del siglo pasado, la explotación forestal tomó un rol central para la consolidación del Estado y esto determinó la necesidad de legislar. Por una parte, la agricultura presentaba problemas para desarrollarse plenamente y, a la vez, había preocupación por la erosión de los suelos. Por otra parte, era importante crear las condiciones para responder a la demanda de madera necesaria para el desarrollo de la industria nacional ${ }^{39}$. Por esto, los argumentos de uno de los principales precursores del desarrollo de esta legislación, Federico Albert, giraron en torno a la necesidad de establecer una "Ley general y la creación de un servicio estatal preocupado de la conservación, manejo y fomento de bosques" $"$.

La primera vez que se desarrolla una Ley general que rige en todo Chile y aplica criterios de regulación al uso y reforestación de bosques fue con el Decreto Ley $\mathrm{N}^{\circ} 4.363$ de 1931. En esta legislación se recogía decretos anteriores, facilitando su consolidación en un cuerpo único, que fomentaba la reforestación vía exención de impuestos y primas para las plantaciones, reglamentación para la tala de árboles, como métodos efectivos para combatir la

\footnotetext{
35 Ibid., 56-57.

${ }^{36}$ Blakemore, H. (2009). Desde la Guerra del Pacífico hasta 1930. En L. Bethel. (Ed.), Chile desde la Independencia. Ediciones Universidad Católica Silva Henríquez y Cambridge University Press. Santiago, Chile

${ }^{37}$ Camus, P. (2006). Ambiente, bosques y gestión forestal en Chile 1541-2005. LOM ediciones, Santiago, Chile; Klubock, T. (2011). El trabajo de la naturaleza y la naturaleza del trabajo: historia medioambiental como historia social. En Cordero, R. (Ed.). Formas de comprender el presente, 52-80, Ediciones UDP, Santiago, Chile

38 Albert, F. (2012). Las dunas, o sea las arenas volantes, voladeros, arenas muertas, invasión de las arenas, playas y médanos del centro de Chile: : Biblioteca Fundamentos de la Construcción de Chile, Santiago, Chile

${ }^{39}$ Camus, P. (2014). De la panacea a la tragedia. Bosques, erosión y forestación en Chile. Siglos XIX y XX. Revista de Historia Iberoamericana, 7:2. Santiago, Chile

${ }^{40}$ Cabeza, ob. cit., 57
} 
erosión ocasionada por otras actividades productivas. Esto "significó (...) un fuerte impulso para el desarrollo de la forestación a gran escala, pues los particulares se mostraron abiertamente interesados por aprovechar los beneficios y franquicias que esta les proporcionaba" ${ }^{41}$. Además de estos incentivos, después de la creación de la Corporación de Fomento de la Producción (CORFO), se otorgó créditos a productores en un contexto de desarrollo hacia adentro, post Crisis del ' $29^{42}$. En los años posteriores a la II Guerra Mundial, también hubo financiamiento de la FAO y Naciones Unidas para explorar la posibilidad de desarrollar la industria de celulosa y papel en Latinoamérica. La Comisión Económica para América Latina y el Caribe (CEPAL) fue de vital importancia en este proceso. Es sustantivo destacar que el establecimiento de esta industria nunca estuvo exento de controversias, pues entre otros factores supone el cambio de actividades productivas y en muchos casos relocalización forzosa de la población ${ }^{43}$.

En este contexto, parte de la historiografía ha otorgado una importancia gravitante a los partidos políticos, como articuladores de la realidad política chilena. Pero también los tecnócratas provenientes de clases medias ejercieron una labor fundamental en Chile, sobre todo en el período del Estado de Compromiso, con una misión articuladora entre esquemas políticos disímiles, sustentado en una "ideología de la industrialización", donde instituciones como la CORFO eran guiadas por tecnócratas que funcionaban como especialistas en áreas que no formaban parte de la discusión política ${ }^{44}$.

De esta manera, se puede evidenciar que existe una cierta unidad inicial entre la consolidación de la industria, el desarrollo de un mercado de la madera y las plantaciones exóticas, con un discurso cientificista que determinaba construcciones específicas del territorio. Así Klubock ${ }^{45}$ sostiene que:

la expansión de la ciencia forestal y la forestación con especies exóticas, la piedra angular de la economía industrial forestal en Chile, significa la producción de un conocimiento medioambiental, a través de la especialidad técnica de la ciencia forestal, que ejerce un monopolio sobre la producción y sobre el proceso laboral que eclipsa

Durante la década de los 1960 y 1970 hubo un impulso estatal por incorporar a otros sectores de la población a la producción maderera. En la década de 1960 se crean dos plantas de celulosa, en las ciudades de Arauco (región del Biobío) y Constitución (región del Maule), y durante el Gobierno de Eduardo Frei Montalva se desarrolla la reforma agraria bajo el esquema de la "revolución en libertad". En la década de 1970, con la llegada de la Unidad Popular al gobierno y la "vía chilena al socialismo", se expropian y dividen grandes latifundios para su gestión directa por los trabajadores agrarios. Posteriormente, "la dictadura entregó

\footnotetext{
${ }^{41}$ Camus, 2006, ob. cit., 172

42 Meller, P. (1996). Un siglo de economía política chilena (1890-1990). Chile: Editorial Andrés Bello

${ }^{43}$ Klubock, 2014, ob. cit.

44 Silva, P. (2012). Tecnócratas y política en Chile: de los Chicago Boys a los Monjes del Cieplan. En T. Ariztía, (Ed.). Produciendo lo social. Usos de las ciencias sociales en el Chile presente. Ediciones UDP, Santiago, Chile.

${ }^{45}$ Klubock, 2011, ob. cit., 70.
} 
parte de estas tierras a empresas forestales. Además, las plantas de celulosa creadas con el apoyo de la CORFO fueron privatizadas"46.

Si resulta claro que el Estado, en sus distintas instancias, ha promovido el desarrollo de la industria forestal, la historia de la Corporación Chilena de la Madera (CORMA) evidencia un fuerte estímulo a una conjunción entre el fomento estatal y la protección de la industria maderera privada. Desde su creación, en 1952, ha influenciado políticas públicas, decretos de ley e incidido en mesas de negociación ${ }^{47}$. Su objetivo ha sido constantemente el de garantizar protección, desarrollo y mantención de la industria que representa, mediante diversos mecanismos. Con esto, "uno de los propósitos fundamentales de CORMA fue [y es] defender los principios del liberalismo económico y la política de fomento a las exportaciones" 48 . CORMA ha estado vinculada directamente con la hegemonía política y económica del país: ministros de Estado la han presidido como también personajes ligados al ámbito privado.

En los años Setenta del siglo pasado, Chile también fue afectado por la ola de golpes militares que se vivieron en toda la región sudamericana cuyo rasgo común fue la complementariedad entre el autoritarismo político represivo con el liberalismo económico, encarnado por el ascenso de los economistas ortodoxos en la esfera pública ${ }^{49}$. En Chile, esto se venía gestando desde la década de 1960, cuando un grupo de intelectuales se forma en la Universidad de Chicago e importa este tipo de ideas en el país. Este equipo de economistas, que asesoró al gobierno militar, postulaba que el proceso de toma de decisiones debía ceñirse a criterios "técnicos y científicos", no "políticos o ideológicos" Chacarilla, en 1977, facilita la comprensión de esta visión. Después de 4 años del golpe de Estado, se anuncia una serie de cambios a realizar en el país: a través del simbolismo propio de un acto refundacional, se impone el carácter unidireccional de la política nacional y se deja en claro que las decisiones serían tomadas por expertos o stakeholders - pues ellos serían los más preparados - mediante mecanismos revestidos de aparente consenso y neutralidad científica. Se impuso, entonces, un modelo en que partidos políticos y demás movimientos sociales, en tanto agentes de cambio, serían dispensables.

Estas ideas inevitablemente repercutieron en el territorio. Así, la industria forestal no queda fuera del paquete de reformas efectuado durante el gobierno militar y se implementa el Decreto Ley 701 del 1974. Fue Fernando Léniz, ex-presidente de la CORMA, quién lo redactó, mientras era Ministro de Economía, y Julio Ponce Lerou, ingeniero forestal y yerno del general Pinochet, se encargó de implementarlo. Este decreto - que entrega bonificaciones hasta el 75\% del valor de la forestación y su manejo ${ }^{51}$ realizada tanto por personas naturales como jurídicas -

\footnotetext{
${ }^{46}$ Román, Á. y Barton, J. (2015). Una ecología política de las transformaciones territoriales en Chile: poder y gobernanza en los sectores forestal y salmonero. En Barton, J., Bustos, B. y Prieto, M. (Eds.), Ecología política en Chile. Naturaleza, propiedad, conocimiento y poder, 237-264. Editorial Universitaria, Santiago, Chile, 241

${ }^{47}$ CORMA (2012). Memoria 2011/2012. Santiago, Chile. Recuperado en: http://www.corma.cl/biblioteca-digital

48 Camus, 2006, ob. cit., 194

${ }^{49}$ Markoff, J. y Montecinos, V. (2012). Del poder de las ideas económicas al poder de los economistas. En T. Ariztía, (Ed.). Produciendo lo social. Usos de las ciencias sociales en el Chile presente. Ediciones UDP, Santiago, Chile

${ }^{50}$ Silva, ob. cit. 81

51 “Artículo $21^{\circ}$ - Durante el plazo de 10 años, el Estado bonificará en un $75 \%$ de su valor la forestación y su manejo que realicen a partir de la fecha del presente decreto ley, tanto las personas naturales como las personas jurídicas. En el caso de las Sociedades Anónimas de giro preferentemente forestal, esta bonificación del 75\% se repartirá en la siguiente proporción:

a) 25\% del valor de las acciones, que se entregará a las personas que suscriban nuevas acciones forestales.
} 
aplicado en una condición de peculiar autoritarismo político es de vital importancia para la historia de esta industria. Esta bonificación generó un rápido incremento de plantaciones forestales, con un aumento exponencial de las superficies plantadas ${ }^{52}$. Además, implicó la sustitución del actor público por el privado mediante un "neoliberalismo [con] un componente desarrollista en que el Estado asumió los costos de la implementación de reformas económicas a la vez que subsidió el despegue de las principales actividades a escala industrial con orientación exportadora" 53 .

Este es un caso paradigmático de gubernamentalidad territorial: la capacidad coercitiva del Estado expresada a través de un decreto ley emanado por un gobierno militar y sustentada a través de la represión, orienta el desarrollo y la planificación territorial en beneficio de la clase social hegemónica, plasmando en profundidad el territorio. El proceso de concentración de la propiedad y sobretodo de la producción maderera en un restringido oligopolio confirman esta contribución imprescindible del Estado en la expansión del monocultivo forestal.

El retorno a la democracia no significó una significativa discontinuidad con la política económica anterior y esto se vio también en la industria forestal ${ }^{54}$. Por otra parte, pudo emerger una generación de nuevos tecnócratas, organizados en torno a diferentes think-tanks, que se opusieron al gobierno militar. Durante el primer gobierno en democracia, este grupo se consolidó a través del impulso a la racionalización de la actividad política, mediante informes generados por profesionales, con capacidades técnicas y políticas (technopols) en tanto las primeras derivan de conocimientos racionales y las segundas de apoyo político, por ejemplo, militantes de un determinado partido político ${ }^{55}$. En este contexto, se consolidó una "continuidad en la política económica, cambios graduales en la política social y un nuevo estilo para la toma de decisiones políticas" ". Así, en 1998 se renueva por 15 años adicionales el D.L. 701 de fomento forestal y se intensificó la bonificación a pequeños propietarios. La última

b) $50 \%$ del valor de las plantaciones forestales y su manejo, que se entregará a las sociedades.

Las nuevas acciones de Sociedades Anónimas de giro preferentemente forestal y sus dividendos estarán exentas del impuesto de herencia, establecido en la ley de impuesto a las herencias, asignaciones y donaciones y de los impuestos de categoría y Global Complementario de la Ley de Impuesto a la Renta." Ministerio de Agricultura (28 octubre 1974) Decreto Ley 701: FIJA REGIMEN LEGAL DE LOS TERRENOS FORESTALES O PREFERENTEMENTE APTOS PARA LA FORESTACION, Y ESTABLECE NORMAS DE FOMENTO SOBRE LA MATERIA

${ }^{52}$ Aguayo, M., Pauchard, A., Azócar G., Parra, O. (2009). Cambio del uso del suelo en el centro sur de Chile a fines del siglo XX. Entendiendo la dinámica espacial y temporal del paisaje. Revista Chilena de Historia Natural, 82. Santiago, Chile; Cisternas, M., Martínez, P., Oyarzún, C. y Debels, P. (1999). Caracterización del proceso de reemplazo de vegetación nativa por plantaciones forestales en una cuenca lacustre de la Cordillera de Nahuelbuta, VIII Región, Chile. Revista Cbilena de Historia Natural, 72 Santiago, Chile; Claude, M. (1999). Las miserias del modelo chileno (una mirada desde la sustentabilidad). En Drake P. y Jacksic, I (Ed.). El modelo chileno. Democraciay desarrollo en los noventa. LOM, Santiago, Chile

${ }^{53}$ Román y Barton, ob. cit., 239

${ }^{54}$ Fuentes, C. (2012). El pacto. Poder, Constitución y prácticas politicas en Cbile (1990-2000). Ediciones UDP, Santiago, Chile

${ }^{55}$ Joignant, A. (2012). La razón de estado: usos políticos del saber y gobierno científico de los technopols en Chile (1990-1994). En Ariztía, T. (Ed.). Produciendo lo social. Usos de las ciencias sociales en el Chile presente. Ediciones UDP, Santiago, Chile. 312

${ }^{56}$ Raczynski, D. (1999). Políticas sociales en los años noventa en Chile. Balance y desafíos. En P. Drake y Jacksic, I. (Ed.). El modelo chileno. Democracia y desarrollo en los noventa. LOM, Santiago, Chile, 129 
revalidación de este decreto se da en el año 2012, durante el primer gobierno de Sebastián Piñera. Esta vez, el período fue de dos años y se creó la categoría del mediano propietario.

En la actualidad, la financiación que otorga este decreto no se encuentra activa, pero sigue siendo el cuerpo legal que regula el funcionar de esta industria. Esta legislación es uno de los resultados de la implementación de un determinado desarrollo hegemónico en el que las ideas económicas, los conocimientos técnicos y los intereses particulares son los factores que articulan la territorialidad.

\section{La dimensión económico-empresarial de la hegemonía territorial: un oligopolio dominado por dos holdings transnacionales y sustentado en el monocultivo}

El sector forestal es clara expresión del tipo de capitalismo que se ha desarrollado y consolidado en Chile, en particular desde el golpe del 1973 cuando el gobierno dictatorial incentivó la apertura a la inversión internacional, para responder a la demanda internacional de materias primas. Se caracteriza por una extrema concentración del capital en un restringido circulo de grandes grupos económicos (bolding) que controlan los diferentes sectores de la economía a través de un régimen de oligopolio ${ }^{57}$. Éstos se han consolidado a través de las prácticas políticas evidenciadas en el apartado anterior, implicando la frecuente superposición de los intereses particulares de las élites a los intereses colectivos, por lo cuales debería velar el Estado. Como han evidenciado Bril-Mascarenha y Madariaga ${ }^{58}$ la peculiaridad del capitalismo chileno ha sido limitar la conformación de conglomerados económicos exógenos. El sector forestal es una expresión evidente de esto, más que otros sectores como el salmonero o el minero. Estas ventajas garantizadas por el sector público han facilitado a las grandes empresas privadas chilenas una estabilidad económica que les ha permitido internacionalizar sus inversiones.

Estos factores han determinado que el oligopolio forestal impusiera una hegemonía política y económica que, como ha evidenciado Sevilla ${ }^{59}$, tiene claras implicaciones territoriales. En este apartado se muestran las características de la hegemonía económica de las empresas forestales que controlan el sector, evidenciando su capacidad de actuar contemporáneamente en diferentes escalas territoriales, gracias a su estructura de holding.

El sector forestal está extremadamente concentrado: en cuanto a la posesión del capital y a la ubicación en el territorio. Respecto al primer punto, resulta dominado por dos grandes empresas, que pertenecen a dos diferentes holdings. Forestal Arauco del Grupo Antar Chile, controlada por la familia Angelini, y la Compañía Manufacturera Papeles y Cartones (CMPC), controlada por la familia Matte. Estas sociedades concentran la mayoría de los recursos del sector: tanto relativos a la materia prima - son propietarias de los principales viveros de plantas

${ }^{57}$ Fazio, H. (2005). Mapa de la extrema riqueza al año 2005. Lom, Santiago, Chile; Atienza, M. Lufin, M. Paredes, D. (2015). La Concentración Económica y del Ingreso en Chile. En Hernández, P., Hidalgo V., Sepúlveda, M.A. Informe Anual de Avance de la Descentralización Chile 2015, 11-28. Políticas y Estudios SUBDER, Santiago, Chile; Undurraga, T. (2014) Rearticulación de grupos económicos y renovación ideológica del empresariado en Chile 1975-2012: la paradoja de la concentración. En Monsalve Zanatti, M. Grupos Económicos y Mediana Empresa Familiar en América Latina, Universidad del Pacífico, Lima, Perú

${ }^{58}$ Bril-Mascarenha, T y Madariaga, A. (2018), Business power and the minimal state: the defeat of industrial policy in Chile. The Journal of Development Studies.

${ }^{59}$ Ob. cit. 
industriales y de la mayoría de superficie forestada del país (de las 2.400 .000 has. plantadas en Chile en 2016, 710.000 has. pertenecen a Arauco y 470.000 a CMPC) - como de la industria de transformación (celulosa, papel, aserraderos, bioenergía). Esto les permite ser las principales exportadoras del sector: en el 2016 CMPC alcanzó un 29\% del total de las exportaciones forestales, mientras que ARAUCO se impuso con un $45 \%{ }^{60}$.

Además, en términos territoriales, este tipo de capitalismo se ha estructurado como un cluster productivo concentrado en las regiones entre el $34^{\circ}$ y el $38^{\circ}$ paralelo sur, aunque sólo la región del Biobío concentra el $40 \%$ de la superficie total plantada, el $22 \%$ de aserraderos y 8 de las 11 plantas de celulosa del país.

Los subsectores de transformación primaria del sector forestal son principalmente dos: la pulpa de celulosa y el aserrío que se reparten casi igualitariamente más del 80\% de los casi 40 millones de $\mathrm{m}^{3}$ de trozas que salen de las plantaciones. De la parte restante la casi totalidad se utiliza para astilla y tableros (10\% y $6 \%$ del total, aproximadamente) y muy minoritariamente para postes y polines, embalajes o se destina directamente a la exportación. De estos subsectores, la producción en la industria de la pulpa es extremadamente concentrada: de un total de 11 plantas (al año 2015) 10 son de propiedad de las empresas CMPC y Arauco. En la industria del aserrío existe una cierta heterogeneidad por la presencia tanto de empresas grandes como medianas y pequeñas. A la vez, la evolución de este subsector entre el año 2006 y el 2015 ha registrado una contracción del número de empresas pasando de 1202 a 1090: ésta ha afectado mayormente a las pequeñas y parcialmente a las grandes empresas. Estas últimas, de todos modos, concentran casi la mitad de la producción total, destacando los aserraderos de Arauco y $\mathrm{CMPC}^{61}$. Esto evidencia el rol hegemónico de estos dos grandes grupos que dominan el mercado local, en el cual el espacio para que las pequeñas empresas se puedan insertar se limita a actividades secundarias (postes y polines o aserraderos móviles).

Junto a esta hegemonía económica local, los dos grupos han sido muy activos a escala global realizando inversiones en diferentes continentes tanto en plantaciones forestales como de plantas productivas. En particular, Arauco está realizando inversiones importantes para posicionarse como uno de los principales productores de celulosa y tableros del mundo ${ }^{62}$. Posee activos en Argentina, Uruguay y sobretodo Brasil - donde a mitad del 2017 compró los aserraderos de MASISA ${ }^{63}$, otro competidor chileno -; durante el 2016 compró Tafisa el principal grupo maderero europeo con plantas productivas en España, Portugal, Alemania y Sudáfrica; y se está insertando también en el mercado estadounidense adquiriendo aserraderos. Según el reporte anual de Price Waterhouse Cooper, las dos empresas chilenas se ubican en el lugar 18 (Arauco) y 21 (CMPC) del ranking mundial de empresas forestales, siendo las

${ }^{60}$ INFOR (2017) Anuario forestal 2017, 120, cuadro 4.24. INFOR, Santiago, Chile

${ }^{61}$ INFOR (2015) La industria forestal primaria en Chile, 164, fig. 5.9 Santiago, Chile.

${ }^{62}$ Durante el año 2017 Arauco ha realizado varias inversiones en el continente americano, tanto a través de la compra de plantaciones forestales como de plantas productivas de celulosa y tableros. En particular hizo una oferta pública para comprar la empresa de celulosa Eldorado. De terminar con éxito, Arauco se hubiera proyectado como el principal productor de celulosa. Finalmente, la operación no prosperó. http://www.economiaynegocios.cl/noticias/noticias.asp?id=370654

63 Pulso (19 diciembre 2017) Tras compra en Brasil, Arauco adquiere activos de MASISA en Mexico por US $\$ 245$ millones. Recuperado en: http://www.pulso.cl/empresas-mercados/tras-compra-brasil-arauco-adquiere-activosmasisa-mexico/ 
estadounidenses International Papers y Kimberly-Clarks y la sueca SCA las tres principales, orientadas principalmente a la producción de papel $^{64}$.

Esta capacidad de inversión es posible también gracias a la estructura del holding que permite una diferenciación de las actividades productivas y especulativas y un acceso al crédito impensable para otras empresas. A la vez, permite posicionarse transescalarmente en la economía, aprovechando las ventajas comparativas de la localización productiva local, para desarrollarse en la economía global.

El holding Angelini se ha ido estructurando a partir de las inversiones de Anacleto Angelini, un inmigrado italiano que llega a Chile en $1948^{65}$. La constitución de lo que es actualmente uno de los principales grupos económicos del país ha sido lenta pero constante, gracias a las intuiciones de este empresario, apoyadas también por distintas figuras políticas y favorecidas por las políticas neoliberales que se han implementado desde el 1973. Tal como es posible desprender de sus páginas institucionales ${ }^{66}$, el holding posee las principales empresas pesqueras del país (Corpesca), localizadas tanto en el Norte, regiones de Arica y Tarapacá, como en la región del Biobío. Posee las principales empresas de combustible de consumo doméstico (Metrogas, Abastible) y para el transporte (Copec), con puntos de venta distribuidos capilarmente por todo Chile. Por otra parte, tiene inversiones en el sector agroindustrial (jugos de marca Premium, aceite de oliva, vino). Este enfoque hacia el sector primario se ha consolidado también gracias a la partnership con la Universidad Católica de Chile, a través de la inversión en un Centro de Innovación que lleva el nombre del patriarca. Finalmente, cabe mencionar que el grupo está incursionando también en el sector educativo. Ha creado en la ciudad de Arauco, en partnership con una de las principales instituciones de formación profesional, un centro educativo orientado a las profesiones forestales. Además, tiene presencia en otros niveles de escolaridad: gestiona tres colegios privados (que imparten enseñanza básica y media) ubicados en las comunas donde posee sus principales plantas industriales Constitución (Maule), Arauco y Yumbel (BioBio). Luego, a través de la Fundación Educacional Arauco, financia proyectos para escuelas municipales rurales (de enseñanza básica) de las regiones en las cuales tiene plantas industriales.

El grupo Matte se ha estructurado alrededor de la familia Matte Larraín. Ésta ha tenido un peso relevante en la historia económica pasada y presente de Chile ${ }^{67}$. En comparación con el holding Angelini, éste resulta más diferenciado, no solamente enfocado hacia el sector primario. Respecto al sector forestal posee la más antigua empresa privada de producción y transformación de celulosa, llamada comúnmente "La Papelera", creada cuando el sector era todavía incipiente y el mayor esfuerzo de inversión estaba a cargo del Estado. Las principales plantas productivas se encuentran en la región del Bio-Bio, en Laja y Nacimiento. Los otros sectores en los cuales el holding posee intereses son el financiero, (banco de inversiones BICE), el de la construcción (El Volcán), eléctrico (Colbún) y telecomunicaciones (Entel). Junto a esto, es propietaria desde más de un siglo la SIP, una red de colegios particulares

64 PWC (2016) Global Forest, Paper \&Packaging Industry survey. Recuperado en: https://www.pwc.com/gx/en/industries/assets/pwc-annual-fpp-industry-survey-2016-10.pdf

${ }^{65}$ El Mercurio (29 agosto 2007) La historia del inmigrante italiano que llegó a ser el más rico de Chile. Recuperado en: http://diario.elmercurio.com/detalle/index.asp?id=\%7Bb8ed7285-0c6e-4072-83d2-4249ea8e9905\%7D

${ }^{66}$ www.antarchile.cl; www.empresascopec.cl

${ }^{67}$ Fazio, H. (2015). Los mecanismos fraudulentos de hacer fortuna. Mapa de la extrema riqueza 2015. Lom, Santiago, Chile 
subvencionados por el Estado y controla la Corporación sin fines de lucro Aptus Chile que asesora distintos colegios en el país. Siempre desde esta perspectiva, es importante mencionar también la influencia ejercida en el think-thanks Centro de Estudios Públicos (CEP) - incluido en la Top 30 de los más influyentes del mundo - del cual Eliodoro Matte ha sido presidente hasta el 2015 manteniendo actualmente su puesto en el Consejo Directivo, junto con Roberto Angelini.

El modelo del bolding permite conformar los anclajes espaciales a través de una multiplicidad de empresas con intereses en áreas distintas, que se posicionan como indispensables, para cubrir gran parte de las necesidades económicas de los territorios en los cuales se va anclando y ramificando a través de su red de infraestructuras productivas, de distribución y comercialización. Un ejemplo de lo anterior se refleja en la gestión de los puertos de Chile: los holdings Angelini y Matte controlan, en partnership o en forma autónoma, los principales puertos del país y Empresas Copec, en particular, posee la mayoría societaria de los principales puertos de la región del Biobío (Lirquén y Coronel), la principal región forestal del país ${ }^{68}$. Otro interesante ejemplo de anclaje espacial, se refiere al sistema de transporte desarrollado por el Ministerio de Obras Públicas en la región del Biobío: aunque las empresas forestales no ejercen un control directo, es importante señalar cómo las infraestructuras que se han realizado en los últimos 20 años han facilitado, directa o indirectamente, el transporte industrial asociado al sector forestal. Dos de las tres autopistas regionales conectan la capital Concepción con la Ruta 5 - principal autopista que atraviesa el país de norte a sur - cruzando extensas plantaciones forestales y conectando con dos de las cuatro plantas de celulosa de la región. La tercera autopista conecta Concepción con el puerto industrial de Coronel y la ciudad de Arauco, pasando por la más grande planta de transformación de madera de Chile. Si es cierto que ofrecen un servicio - de pago - al conjunto de la población, es evidente el beneficio para las empresas. Por otra parte, otras carreteras secundarias no han tenido la misma suerte de transformarse en autopista o de ser pavimentadas, dejando las zonas rurales en un estado de conectividad precaria y además complicada por el flujo constante de camiones con carga maderera que dificultan el tránsito y desgastan rápidamente caminos y puentes.

Pero, la expresión más significativa del anclaje espacial de las empresas forestales son las plantaciones que, después de cuatro décadas de expansión casi incontrolada se han configurado como un monocultivo que ocupa hegemónicamente millones de hectáreas de los territorios del secano costero y secano interior entre la región de O’ Higgins y la Araucanía. Para el año 1974, cuando se promulga el DL 701, se estima que la superficie plantada alcanzaba las 400.000 hectáreas; en el 2015 las plantaciones ocupaban casi 2,5 millones de hectáreas (tabla 1). Como fue señalado en apartado anterior, la justificación tecnicista ha sido la de frenar la erosión de los suelos; en la práctica, esto ha ocurrido a través de la suplantación de un monocultivo con otro (del cerealícola al forestal), afectando también al bosque nativo.

Tomando como ejemplo el caso del Biobío, estas plantaciones ocupan aproximadamente un tercio de la superficie regional, presentando una significativa homogeneidad de especies (casi el 70\% corresponde a pino radiata y la parte restante eucaliptus globulus y nitens) y una alta concentración espacial: en el sector costero y cuencas

${ }^{68}$ EMPRESAS COPEC (2016) Memoria anual 2015.

http://investor.empresascopec.cl/wp-content/uploads/2016/04/Memoria-Anual-2015-Versi\%C3\%B3nImprimible.pdf 
fluviales (Valle del Itata, Valle del Biobío) las plantaciones ocupan entre el 50\% y el 80\% de la superficie útil de las comunas. Como se puede apreciar en los mapas (figura 1 y 2), esta forestación ha implicado un cambio de uso de suelo, principalmente de agrícola a forestal, lo cual ha reducido cada vez más la posibilidad de alternativas productivas al monocultivo forestal, llegando a una saturación del territorio: en algunas comunas ya no hay espacio donde plantar. Teniendo en cuenta lo anterior, el estudio de Fawaz ${ }^{69}$ sobre el desarrollo de la Industria Forestal en la Provincia de Ñuble - que hasta el año 2017 era parte de la Región del Biobío antes de ser declarada región autónoma - es elocuente. La expansión de esta industria trae repercusiones generando una nueva territorialidad, reescribiendo las prácticas espaciales previas. Relocalizaciones de población con migraciones del campo a la ciudad, exclusión de actividades típicas del género femenino, etc., son algunos de los puntos relevados por la autora como productos del desarrollo de la Industria Forestal en un territorio en que la aplicación del DL $701 / 74$ es particularmente efectiva.

Tabla 1. Evolución de la superficie plantada, acumulada a diciembre de cada año (1990-2015). Datos nacionales y de las principales regiones forestales de Chile

\begin{tabular}{|l|r|r|r|r|r|}
\hline Año & Total Chile (ha.) & O'Higgins (ha.) & \multicolumn{1}{l}{ Maule (ha.) } & \multicolumn{1}{l}{ BioBio (ha.) } & Araucania (ha.) \\
\hline \hline $\mathbf{1 9 9 0}$ & 1.460 .530 & 64.537 & 289.218 & 612.451 & 227.751 \\
\hline $\mathbf{1 9 9 1}$ & 1.555 .255 & 71.385 & 300.033 & 647.544 & 248.640 \\
\hline $\mathbf{1 9 9 2}$ & 1.609 .295 & 80.374 & 313.150 & 679.222 & 222.435 \\
\hline $\mathbf{1 9 9 3}$ & 1.694 .104 & 88.256 & 324.523 & 710.931 & 239.836 \\
\hline $\mathbf{1 9 9 4}$ & 1.747 .523 & 92.775 & 332.996 & 718.597 & 246.767 \\
\hline $\mathbf{1 9 9 5}$ & 1.818 .185 & 83.944 & 346.376 & 757.002 & 301.603 \\
\hline $\mathbf{1 9 9 6}$ & 1.835 .985 & 84.024 & 347.349 & 761.916 & 302.840 \\
\hline $\mathbf{1 9 9 7}$ & 1.881 .925 & 87.802 & 363.837 & 747.443 & 327.820 \\
\hline $\mathbf{1 9 9 8}$ & 1.914 .846 & 89.557 & 370.811 & 755.479 & 332.938 \\
\hline $\mathbf{1 9 9 9}$ & 1.952 .288 & 96.228 & 385.829 & 761.451 & 337.933 \\
\hline $\mathbf{2 0 0 0}$ & 1.989 .101 & 98.531 & 390.039 & 771.963 & 346.045 \\
\hline $\mathbf{2 0 0 1}$ & 2.037 .403 & 99.622 & 397.378 & 781.859 & 366.259 \\
\hline $\mathbf{2 0 0 2}$ & 1.997 .580 & 105.389 & 366.023 & 763.488 & 379.285 \\
\hline $\mathbf{2 0 0 3}$ & 2.046 .430 & 108.995 & 378.890 & 770.502 & 391.764 \\
\hline $\mathbf{2 0 0 4}$ & 2.078 .647 & 90.216 & 388.123 & 791.831 & 389.946 \\
\hline $\mathbf{2 0 0 5}$ & 2.135 .323 & 94.356 & 401.105 & 797.900 & 420.181 \\
\hline $\mathbf{2 0 0 6}$ & 2.201 .585 & 98.938 & 409.075 & 832.803 & 420.604 \\
\hline $\mathbf{2 0 0 7}$ & 2.299 .334 & 102.457 & 432.638 & 858.592 & 442.106 \\
\hline $\mathbf{2 0 0 8}$ & 2.300 .090 & 101.591 & 439.084 & 861.248 & 434.185 \\
\hline $\mathbf{2 0 0 9}$ & 2.277 .896 & 103.165 & 451.116 & 878.418 & 454.285 \\
\hline $\mathbf{2 0 1 0}$ & 2.320 .341 & - & - & - & - \\
\hline $\mathbf{2 0 1 1}$ & 2.349 .250 & - & - & - & - \\
\hline $\mathbf{2 0 1 2}$ & 2.414 .389 & - & - & - & - \\
\hline $\mathbf{2 0 1 3}$ & 2.447 .592 & - & - & & - \\
\hline $\mathbf{2 0 1 4}$ & 2.426 .722 & - & -336.761 & 913.173 & 482.113 \\
\hline $\mathbf{2 0 1 5}$ & 2.396 .562 & 128.757 & & & - \\
\hline
\end{tabular}

Fuente: elaboración propia con datos ODEPA, Estadísticas Forestales

${ }^{69}$ Fawaz, J. (2000). Expansión forestal en Nuble y reestructuración social y productiva a nivel local. Percepción de los actores. Tiempo y Espacio, 8, Chillán, Chile. 
Figura 1. Evolución del uso del suelo, Provincia de Concepción (1997-2015).

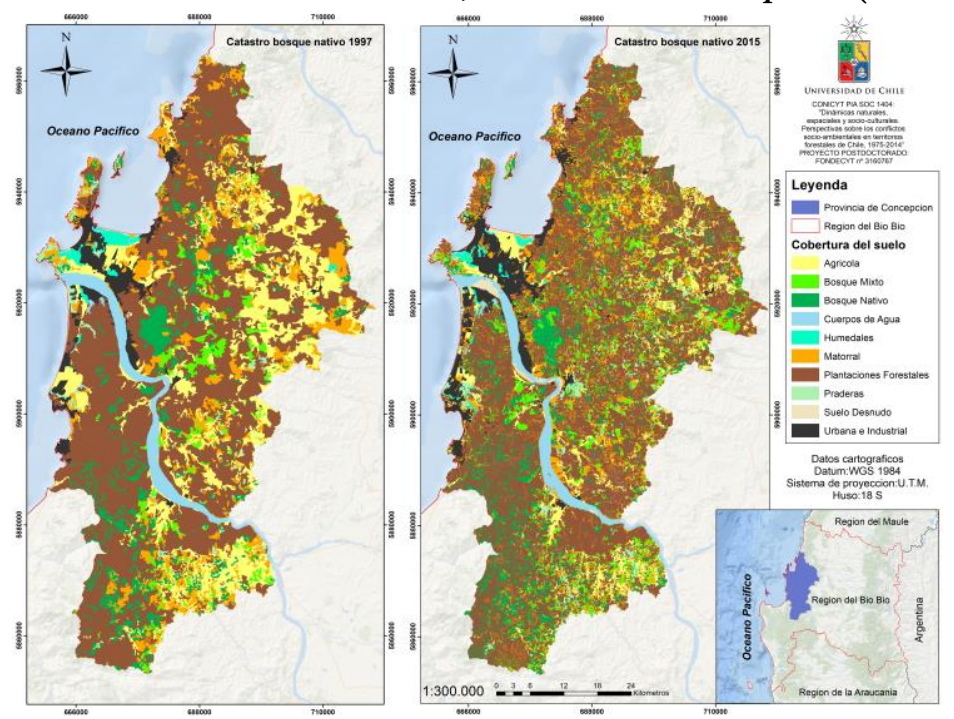

Fuente: CONAF, Catastro bosque nativo 1997, 2015

Figura 2. Evolución del uso del suelo, Provincia de Ñuble (1997-2015)

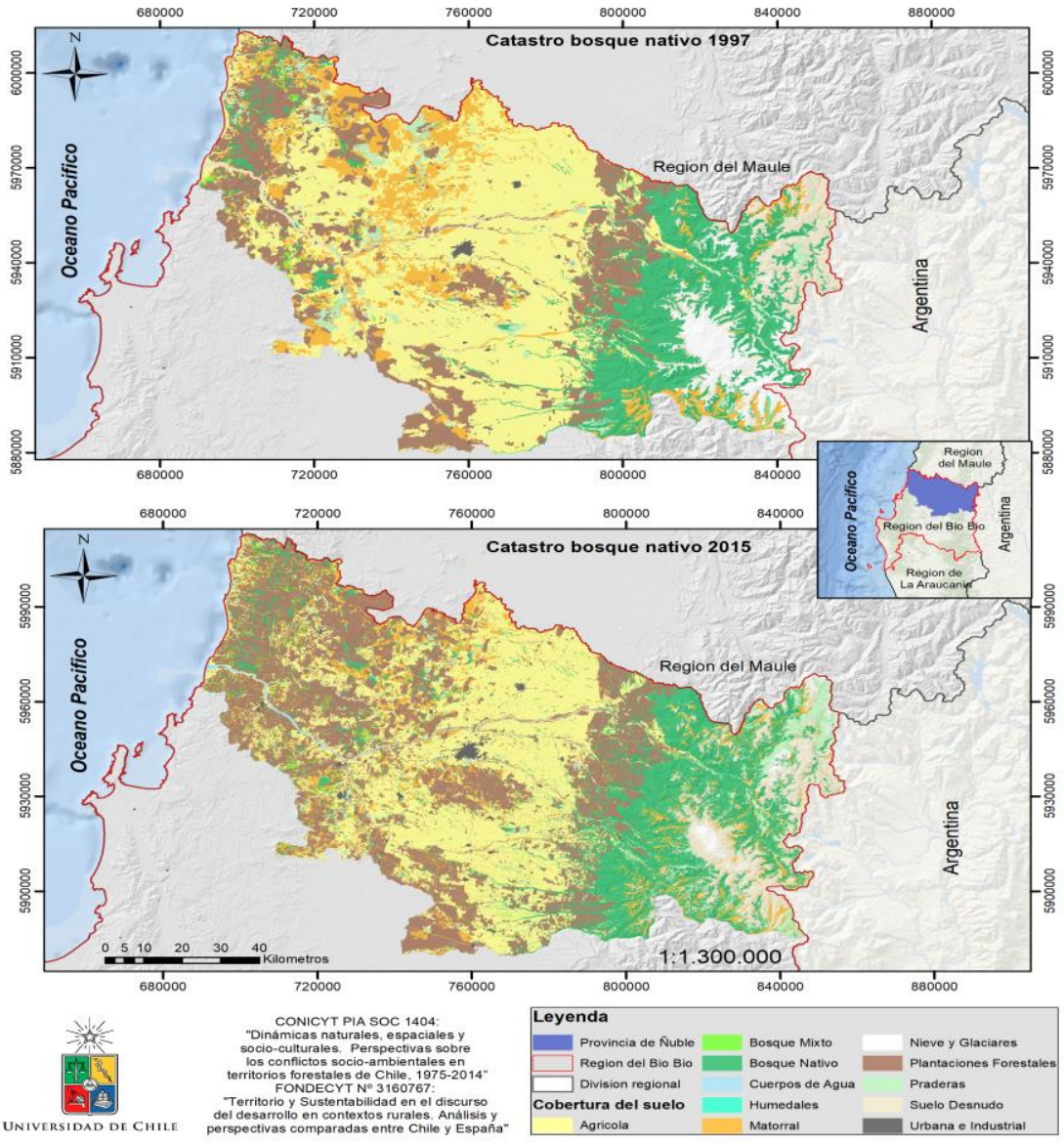

Fuente: CONAF, Catastro bosque nativo 1997, 2015 


\section{La dimensión simbólico-cultural. La hegemonía territorial como construcción de imaginarios territoriales}

El discurso que ha acompañado el crecimiento del sector forestal en Chile ha hecho hincapié en un doble proceso de marketing para poder justificarlo social y ambientalmente.

La hegemonía territorial se realiza en primer lugar a través de la faceta "territorial" del discurso "desarrollista" como son los distintos programas sociales de "acciones de buena vecindad" que han implementado las empresas forestales ${ }^{70}$. Este enfoque, supuestamente "localista", se complementa con la visión sustentable. A través de estas dos estrategias se ha construido un imaginario territorial del Biobío como región forestal que se reafirma y alimenta en las prácticas cotidianas, que funcionan como una pedagogía en la interiorización en la población de la inevitabilidad del modelo forestal. Las empresas forestales, comprometen recursos en acciones de "buena vecindad", generando lazos entre ellas y las comunidades, que se traducen en productos relacionales carentes de conflictividad con un vínculo, incluso, emocional. En este aspecto, es importante destacar que después de la muerte masiva de cisnes en Valdivia, Forestal Arauco comenzó a invertir recursos en promover un desarrollo que abarcara nuevos aspectos ${ }^{71}$. Desde entonces, ha tenido una preocupación mayor por las comunidades locales, en cuyos territorios se localizan sus actividades productivas, apoyando intervenciones que estimulen vínculos y lazos afectivos. Así se justifica la importancia de Arauco en la reconstrucción de Constitución post terremoto ${ }^{72}$ con un Estado que no logra actuar de manera completa y efectiva en algunos sectores, mientras la empresa forestal se plantea como el único actor que puede dar respuesta a necesidades básicas como vivienda o trabajo. Las fundaciones, en particular, desarrollan la función de articular el territorio respondiendo a las necesidades, a menudo básicas, de los habitantes y canalizando los intereses de las empresas. A través de un sistema de concurso, se seleccionan los proyectos considerados más viables y que abordan diferentes líneas de intervención, desde el abastecimiento de agua a la creación de PYMES en el sector turístico o de la recolección de productos forestales no maderables (frutos silvestres, hongos, hierbas etc.), a la pavimentación de caminos o la construcción de viviendas sociales (prefabricadas en madera). Un ejemplo es el Proyecto de Casas Abiertas, presente en las comunas donde se ubican las plantas de celulosa, como Ránquil y Arauco en la región del Biobío. Se desarrolla en un espacio físico gestionado por la empresa en beneficio de la comunidad, ofreciendo actividades que conjugan prácticas profesionales antiguas (artesanía cerámica, tejidos etc.) con otras contemporáneas (informática etc.), procurando mejorar la relación con las comunidades locales, sin necesariamente cambiar el tipo de prácticas territoriales. Complementariamente a esto, la inserción en el sector educativo permite a las empresas forestales desarrollar directamente la faceta pedagógica de la hegemonía.

\footnotetext{
${ }^{70}$ Carrasco, N. (2012). Trayectoria de las relaciones entre empresas forestales y comunidades mapuche en Chile. Aportes para la reconstrucción etnográfica del desarrollo interétnicos. Polis, 11:31, 355-371. Universidad de los Lagos, Santiago, Chile

71 Delamaza, G. (2012). Responsabilidad social empresarial, política e internacionalización. El caso del «conflicto de los cisnes» en Valdivia. Apuntes, 39:70, 167-202Valdivia, Chile

72 Saleh, F. (2011) La estrategia de Tironi para levantar imagen de Arauco después del terremoto (22 marzo 2011) El Mostrador Recuperado en: http://www.elmostrador.cl/noticias/pais/2011/03/22/la-estrategia-de-tironi-paralevantar-imagen-de-arauco-despues-del-terremoto
} 
Junto con lo anterior, la construcción de un imaginario territorial que se hace sentido común se ve en las prácticas territoriales cotidianas expresadas por las figuras 3, 4, 5 y 6. La figura 3 es un cartel que se encuentra en una oficina de CORMA. Reproduciendo el camino de la madera desde la plantación a la planta de transformación, sintetiza gráficamente los conceptos tópicos del discurso forestal. En primer lugar, se presentan las distintas actividades laborales asociadas al sector: desde la plantación a la limpieza de los arboles a la tala mecanizada. La plantación parece integrada armónicamente en su entorno ambiental, coexistiendo con el bosque nativo y con la fauna (zorro). Las faenas forestales, por otra parte, se integran con las actividades típicamente agrarias: la siembra de huertos, la agricultura familiar, la ganadería extensiva; y también con la pesca artesanal del borde costero. La planta industrial se representa con el símbolo del reciclaje, sin emisiones contaminantes que sí aparecen $\left(\mathrm{CO}_{2}\right)$ en la ciudad representada en el fondo, aunque parecen compensadas por la inmisión de oxigeno $\left(\mathrm{O}_{2}\right)$ que proveen las plantaciones.

Figura 3. Cartel representativo del ciclo de la madera

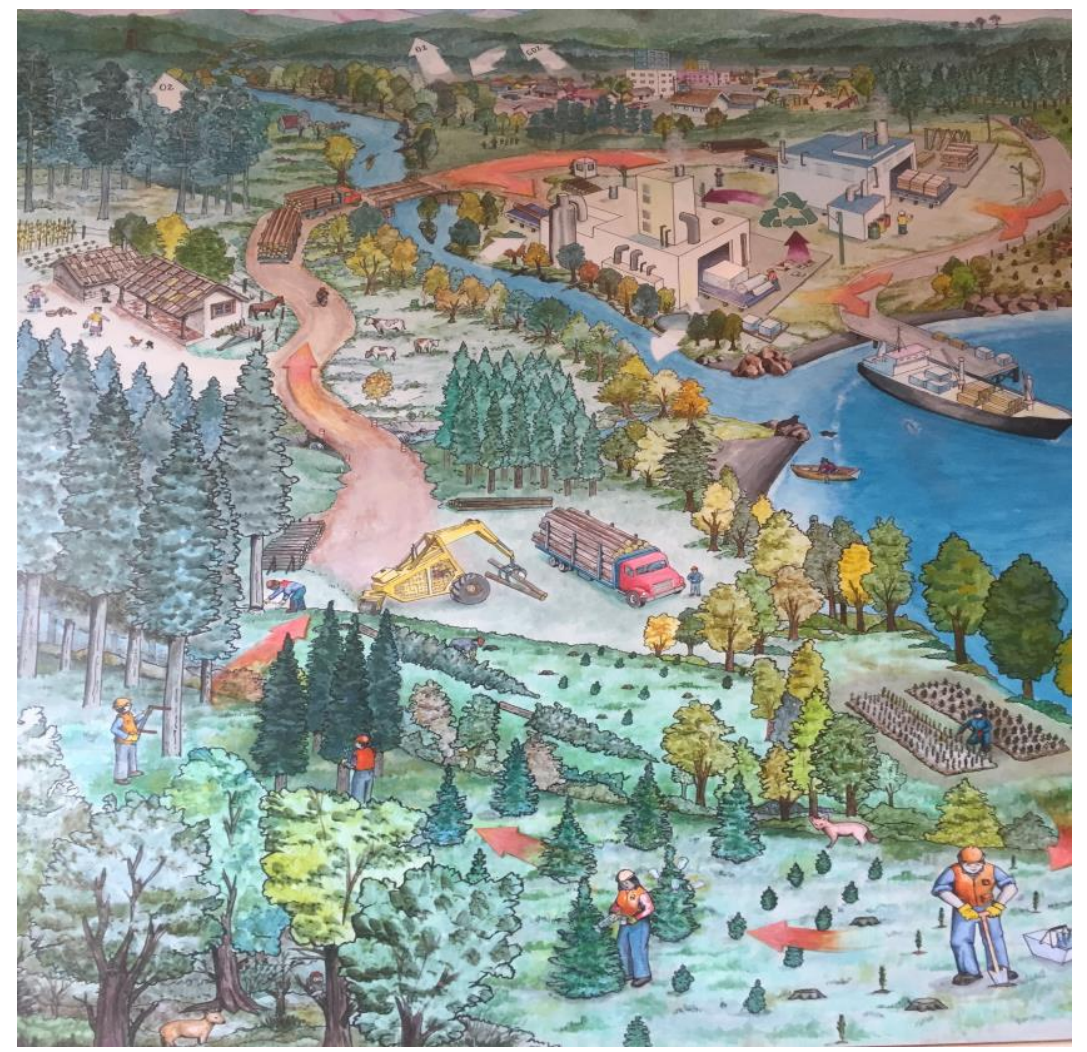

Fuente: Fotografía Massimiliano Farris

El hecho, impuesto exógenamente, pero, al parecer, asumido endógenamente, de ser una región forestal se refleja en las figuras 4, 5 y 6 . En la 4 se aprecia el cartel del denominado "bosque de mitigación", realizado en la reconstrucción post-tsunami 2010 en la localidad de Dichato (Tomé) que se compone fundamentalmente de pinos, como los de la plantación 
industrial que cubre el cerro al fondo de la imagen. Esta especie hegemoniza también estos lugares secundarios.

El imaginario del territorio forestal se consolida difundiendo, pedagógicamente, el uso constructivo de la madera en los lugares de la cotidianidad: en el aeropuerto (figura 5), en los centros comerciales (El Trébol, Concepción), las bibliotecas (Biblioteca municipal de Constitución), las casas de la reconstrucción post-terremoto 2010 y post-incendio 2017 (Constitución y Florida). Esto se complementa con la introyección del imaginario que tienen los habitantes de ser una región forestal: esta marca simbólica significativa, que representa el esfuerzo del trabajo de corte de los pinos, viene plasmada en los souvenir (figura 6) que se venden en los lugares más turísticos junto con otros que representan imaginarios identitarios distintos como el rodeo o la cueca.

En cuanto a la discursividad de la sustentabilidad esta se ha expresado en unas iniciativas orientadas a la "sustentabilidad" empresarial: técnicas productivas bajo estándares y certificaciones internacionales ${ }^{73}$ y generación de agroenergía de la biomasa, contribuyendo no sólo al autoabastecimiento sino, además, a ofrecer energía "limpia" al país en su conjunto. Pero, el logro de mayor importancia en términos de semántica ideológica, corresponde a la homologación de las plantaciones de monocultivos forestales con la definición de bosque, que, por ejemplo, la Organización de Naciones Unidas para la Alimentación y la Agricultura (FAO) respalda. Mouffe ${ }^{74}$ indica que en términos hegemónicos se debe tener en especial consideración lo que Gramsci tipificó como "hegemonía por neutralización”: la condición en la que "las demandas que desafían el orden hegemónico son apropiadas por el sistema existente a fin de satisfacerlas de un modo que neutralice su potencial subversivo",75.

Figura 2 "Bosque" de mitigación, Dichato

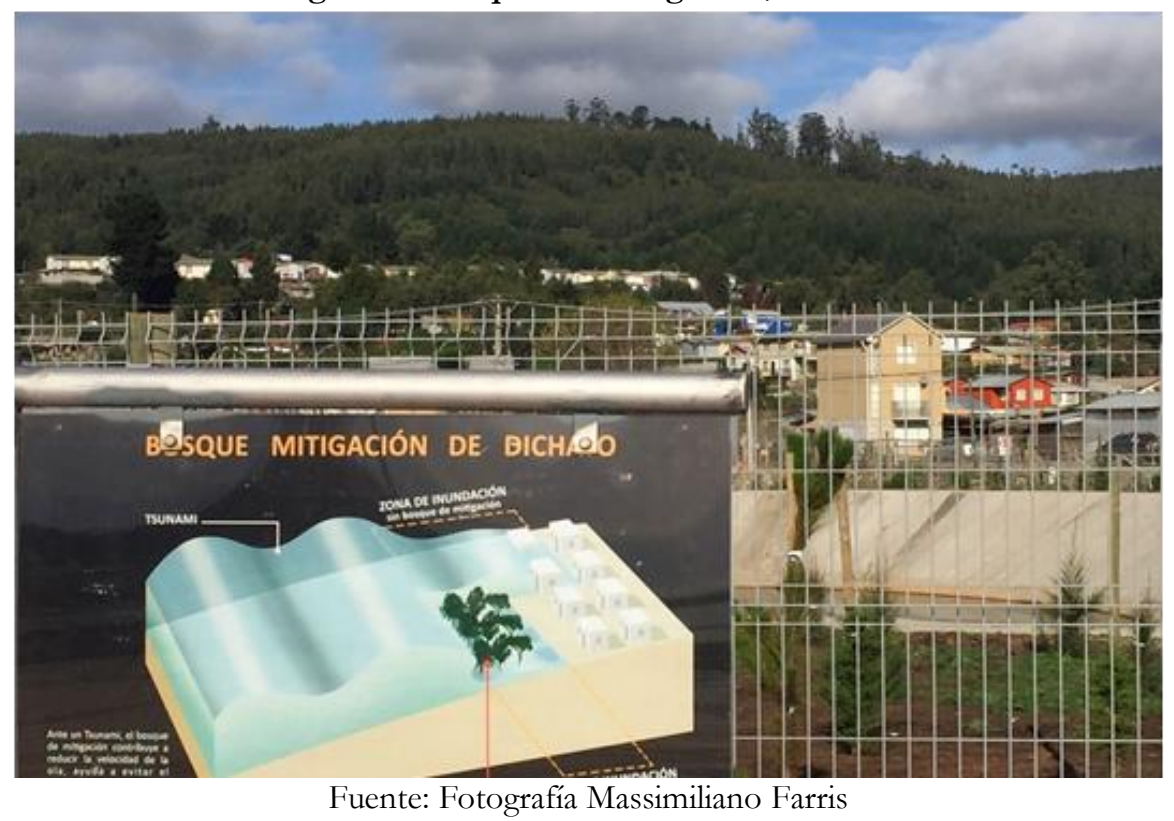

\footnotetext{
${ }^{73}$ Carrasco, ob. cit.

${ }^{74}$ Mouffe, C. (2014) Agonistica. Fondo de la Cultura Económica, Buenos Aires, Argentina.

${ }^{75}$ Ibid., 84
} 
Figura 3. Aeropuerto Concepción

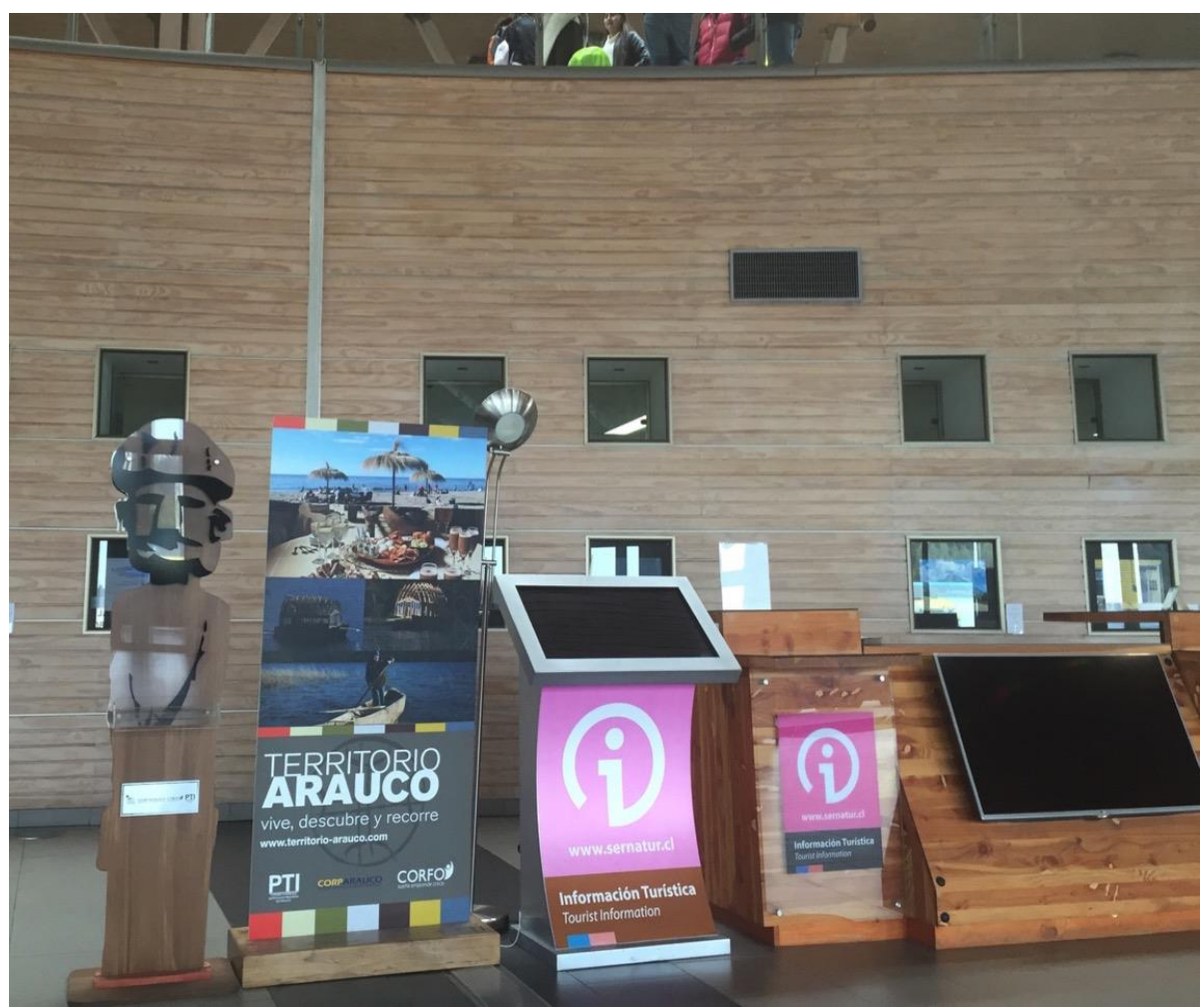

Fuente: Fotografía Massimiliano Farris

Figura 4. Souvenir en Salto del Laja

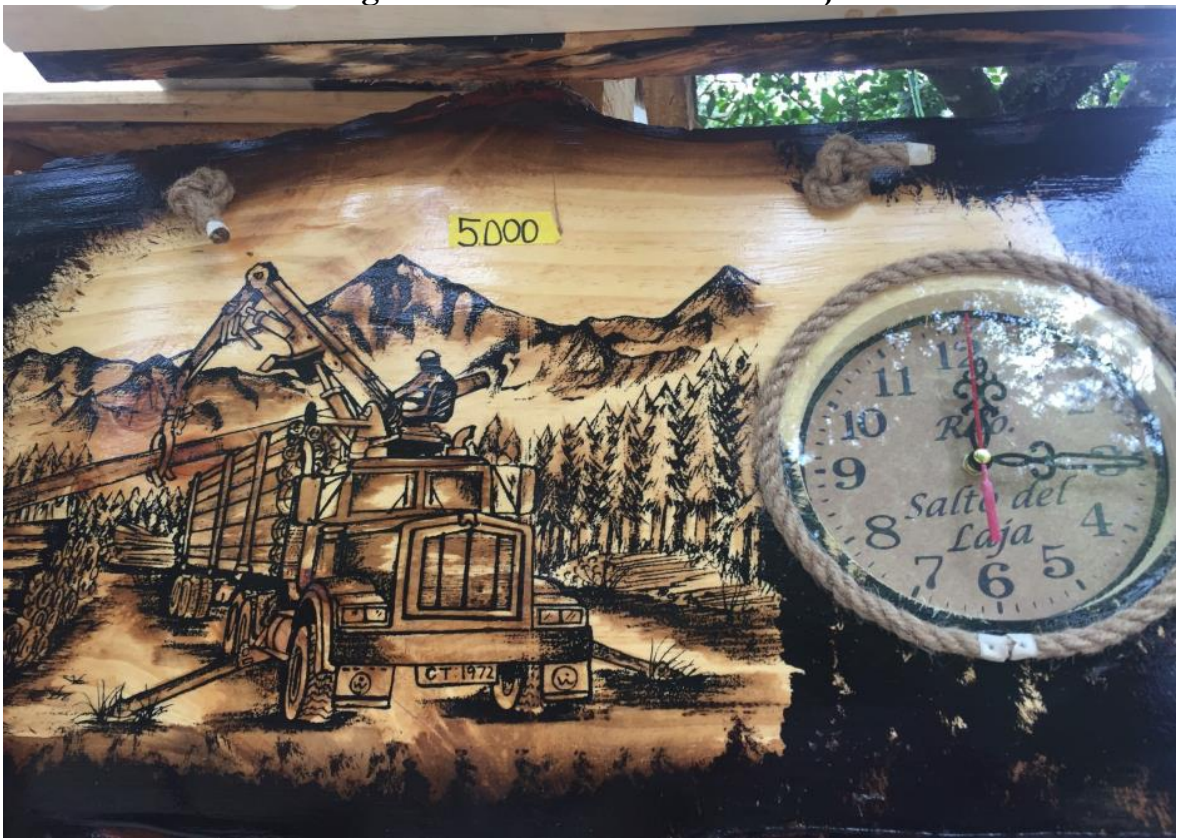

Fuente: Fotografía Massimiliano Farris 


\section{Reflexiones finales y perspectivas de investigación}

El sector forestal en Chile tiene una importancia significativa en términos macroeconómicos ya que representa el segundo sector productivo y exportador, contribuyendo aproximativamente al 3\% del PIB. Su expansión se impulsó durante la dictadura de Augusto Pinochet, respondiendo a la política económica que pretendía la apertura de la economía chilena y su inserción en los mercados globales. Si las ayudas estatales han permitido su fomento y la progresiva concentración del capital, los constantes estímulos recibidos por la demanda internacional de celulosa han favorecido su expansión a lo largo de cuatro decenios. Estrictamente vinculado a los dos anteriores, hay que considerar otro factor determinante para la consolidación del sector: su anclaje espacial, construido a través del ejercicio de una hegemonía territorial complementada, según las diferentes condiciones espaciales que se han dado en el tiempo, por una gubernamentalidad territorial.

Si bien es el mercado global el que ha estimulado el sector, su actual conformación depende de las peculiares condiciones del capitalismo familiar chileno y la extrema porosidad entre el sistema político y el sistema económico-empresarial, puesta al descubierto por los escándalos de corrupción ${ }^{76}$. Durante la dictadura, a través de prácticas de gubernamentalidad tanto legislativas como policíacas, la élite político-militar ha garantizado una territorialidad funcional a los intereses de la élite económica. A la vez, instalando el discurso de la necesidad del "desarrollo" del país a realizar con el libre mercado y tutelado con la represión, ha puesto las bases para la construcción de una hegemonía cultural y territorial que se ha consolidado con la llegada de la "democracia". En el actual periodo, han cambiado las formas para sustentarla recurriendo a prácticas blandas de control y convencimiento, aunque nunca hubo una ruptura significativa con la narrativa desarrollista y liberal (liberista) y se sigue recurriendo, en determinados contextos y momentos, a prácticas de gubernamentalidad, como la aplicación de la Ley Antiterrorista en los territorios mapuche. Si en los años Noventa, el trabajo pedagógico funcional a la consolidación de la hegemonía se ha enfocado en el discurso del desarrollo como crecimiento económico, en la última década se ha hecho hincapié cada vez más en la sustentabilidad.

Como hemos evidenciado en el artículo, esta hegemonía política y económica se basa en el trabajo ideológico realizado por los tecnócratas que ha determinado la estructura del Estado, la función que se le atribuye y el rol que desarrolla. Esto se materializa en la renuncia por parte del actor público de proveer y gestionar directamente, en todos los territorios, los servicios sociales, lo cual, de facto, deja campo libre a las grandes empresas que están en condición entregarlos. De esta perspectiva se puede entender como las acciones que son catalogadas genéricamente como de "buena vecindad" y que sirven para cumplir con los requerimientos de las certificaciones internacionales responden a un proceso más profundo de planificación y control territorial. Como hemos evidenciado en principio, la hegemonía se basa en prácticas pedagógicas y en difundir en el sentido común, no sólo público, una visión del mundo funcional a la clase dominante. Esto, en los territorios forestales, se logra "colonizando" los espacios cotidianos por medio de acciones realizadas directamente por las

\footnotetext{
${ }^{76}$ Matamala, D. (09/12/2015) Los dueños de Chile, CIPER en http://ciperchile.cl/2015/12/09/los-duenos-de-
} chile/ 
empresas o intermediadas por las fundaciones levantadas por las mismas empresas. Las fundaciones, en particular, desarrollan la función de articular el territorio respondiendo a las necesidades, a menudo básicas, de los habitantes y canalizando los intereses de las empresas. Complementariamente a esto, la inserción en el sector educativo permite a las empresas forestales desarrollar directamente la faceta pedagógica de la hegemonía.

Esta renuncia ideológica del Estado a hacerse cargo de las necesidades colectiva se hace evidente en la magnitud con la que se ha dado la expansión del monocultivo sin una estrategia efectiva de planificación o control. Las plantaciones industriales han suplantado el modelo productivo del latifundio cerealícola, cuya estructura económica permitía la presencia contemporánea de otras actividades secundarias o de subsistencia dentro del mismo fundo patronal (cultivo de chacras, recolección de productos silvestres, producción de carbón, etc.). Actualmente, el monocultivo forestal define una territorialidad que homogeniza el paisaje, desvinculando de esta construcción las complejas relaciones entre ecosistemas boscosos nativos y territorios socialmente construidos por la agricultura. No deja espacio, literalmente, y ha creado una condición difícilmente reversible que complica la posibilidad que prosperen alternativas económicas. Estas condiciones marcan en el mediano y largo plazo el desarrollo territorial y se configuran como el anclaje espacial del poder empresarial, favoreciendo las prácticas hegemónicas mencionadas anteriormente.

Finalmente, la estructura en holding transnacional garantiza los recursos y el entramado altamente diferenciado de intereses enraizados en los territorios para desarrollar prácticas hegemónicas. A la vez, esta base territorial garantiza la estabilidad económica para que las empresas puedan explorar perspectivas de expansión y crecimiento en los mercados internacionales y hacia nuevos productos con mayor valor añadido (viviendas prefabricadas en madera, muebles etc.).

Las estrategias hegemónicas se han aplicado en contextos caracterizados por un ambiente político favorable, una fragilidad económica evidenciada por la necesidad de suplir a las necesidades básicas y un evidente desequilibrio en las relaciones de poder entre los actores territoriales. Se puede decir que la hegemonía territorial condiciona y anestesia también la conflictividad social. Como han evidenciado Folchi y Aliste, la mayor oposición social a las empresas forestales se ha concentrado históricamente en las provincias de Arauco y Malleco, territorios en los cuales el rechazo al modelo forestal se solapa con las reivindicaciones históricas del pueblo mapuche. En los otros territorios forestales, pareciera que no existiera conflicto o que estuviera latente. La región del Biobío es representativa de este punto de vista. Es un territorio complejo en el cual se ha hecho evidente lo que Svampa llama una disputa entre territorialidades inspiradas por diferentes lenguajes de valoración sobre el uso del espacio. Lo demuestran las movilizaciones contra intervenciones infraestructurales con significativos impactos ambientales como la construcción de un gasoducto en Penco-Lirquén o de una central termoeléctrica en Bulnes o el proyecto de puente industrial en San Pedro de la Paz y los proyectos salmoneros entre Cobquecura y Tomé. Por otra parte, pareciera no existir una disputa respecto a la territorialidad definida por el monocultivo forestal. No teniendo evidencias de un conflicto socioambiental manifiesto y, por ende, de métodos coercitivos de gubernamentalidad territorial, como los que se aplican en los territorios con presencia de comunidades indígenas, se podría concluir que las prácticas materiales y discursivas de hegemonía territorial han condicionado significativamente la territorialización de estos 
espacios. A la vez, en este contexto de aparente no conflictividad, han tenido un efecto detonador los incendios de enero 2017, que destruyeron más de 500.000 hectáreas entre el centro-sur del país, la mayoría de ellas dedicadas a plantaciones. El fuego ha puesto en peligro la misma vida de los habitantes de estos territorios y ha visibilizado un descontento presente en los territorios. Este descontento se ha canalizado hacia una judicialización del conflicto entre población local y empresas forestales, encabezada por el Municipio de Florida al cual se han sumado una decena de otros, enfocándose principalmente en las significativas lagunas jurídicas que existen en la normativa forestal en relación a la tutela de las poblaciones que viven en proximidad de las plantaciones. Por otra parte, se han consolidado (y han ido surgiendo) movimientos locales que tienen como elemento central en su agenda la relación entre crecimiento económico y tutela del territorio como "Arauco Tiene Mil Penas" y la "Coordinadora en defensa de la Tierra y el Agua".

Estos elementos nos inducen a plantearnos nuevas preguntas para abordar el análisis sobre el futuro del sector forestal en Chile y sus implicaciones territoriales. La pregunta central es si se pueden vislumbrar posibilidades de salida de este modelo territorial hegemónico, conformando una contrahegemonía tanto política como económica.

Para poder abordar una respuesta es necesario comprender qué capacidad de dialogo y de sinergia se puede dar entre otras experiencias productivas actualmente marginales, algunas de ellas controladas por el oligopolio ${ }^{77}$, otras que se diferencian de la producción forestal, aunque no plantean una oposición clara al modelo ${ }^{78}$ y también las experiencias productivas inspiradas por una visión anticapitalista ${ }^{79}$. Complementario a esto, otra interrogante tiene que ver con qué sujetos políticos pueden asumir el rol de conectar estas experiencias y plantear una diferente territorialidad. Actualmente, la extrema porosidad del límite entre la esfera políticoadministrativa y la económico-empresarial hace evidente que el Estado resulta demasiado liviano para desarrollar una "contrahegemonía". Los movimientos sociales que están estructurando una resistencia al modelo pueden desarrollar prácticas de "territorialidad activa", como la define Governa, conectando estas distintas experiencias y planteando lenguajes de valoración diferentes sobre el uso del espacio. A la vez, es necesario que estas prácticas se proyecten transescalarmente no sólo planteando una nueva territorialidad para los territorios forestales como también redefinir el rol del Estado, modificando la Constitución que es el dispositivo gubernamental que permanece desde la dictadura y condiciona la capacidad del cambio en profundidad.

\section{Bibliografía}

\section{Fuentes impresas.}

\footnotetext{
${ }^{77}$ Las actividades complementarias a la producción forestal como la recolección y transformación de los productos forestales no maderables.

${ }^{78}$ La vitivinicultura en el Itata, los horticultores de Boca Sur, las experiencias de "labranza cero" y floricultura en Florida etc.

${ }^{79}$ Como las agricultoras reunidas en la Asociación Nacional Mujeres Rurales e Indígenas (ANAMURI)
} 
Aguayo, M., Pauchard, A., Azócar G., Parra, O. (2009). Cambio del uso del suelo en el centro sur de Chile a fines del siglo XX. Entendiendo la dinámica espacial y temporal del paisaje. Revista Chilena de Historia Natural, 82. Santiago, Chile

Albert, F. (2012). Las dunas, o sea las arenas volantes, voladeros, arenas muertas, invasión de las arenas, playas y médanos del centro de Chile.: Biblioteca Fundamentos de la Construcción de Chile, Santiago, Chile

Arenas, F. (1999). Organización territorial y desarrollo regional en Chile. Estudios Geográficos, 60:23, 101119. Madrid, España

Arenas, F. (2009). El Chile de las regiones: una historia inconclusa. Estudios Geográficos, 70:266, 11-39. Madrid, España

Aroca, P. (2009). Desigualdades regionales en Chile. Foreign Affairs Latinoamérica, 9:1, 53-63

Asociación Municipalidades BioBio (2015) Impacto de las operaciones forestales en la región del Biobio desde la perspectiva municipal y su vinculación al riesgo de desastres y emergencias. Resumen Ejecutivo

Atienza, M. Lufin, M. Paredes, D. (2015). La Concentración Económica y del Ingreso en Chile. En Hernández, P., Hidalgo V., Sepúlveda, M.A. Informe Anual de Avance de la Descentralización Cbile 2015, 11 28. Políticas y Estudios SUBDER, Santiago, Chile.

Blakemore, H. (2009). Desde la Guerra del Pacífico hasta 1930. En L. Bethel. (Ed.), Chile desde la Independencia. Ediciones Universidad Católica Silva Henríquez y Cambridge University Press. Santiago, Chile

Bril-Mascarenha, T y Madariaga, A. (2018), Business power and the minimal state: the defeat of industrial policy in Chile. The Journal of Development Studies.

Cabeza, A. (1988). Aspectos históricos de la legislación forestal vinculada a la conservación; la evolución de las Áreas Silvestres Protegidas de la zona de Villarrica y la creación del primer parque nacional de Chile. Documento de Trabajo No101. CONAF, Santiago, Chile.

Camus, P. (2006). Ambiente, bosques y gestión forestal en Chile 1541-2005. LOM ediciones, Santiago, Chile

Camus, P. (2014). De la panacea a la tragedia. Bosques, erosión y forestación en Chile. Siglos XIX y XX. Revista de Historia Iberoamericana, 7:2. Santiago, Chile

Canales, M., \& Hernández, M. C. (2011). Del fundo al mundo. Cachapoal, un caso de globalización agropolitana. Espacio Abierto, 20(4)

Carrasco, N. (2012). Trayectoria de las relaciones entre empresas forestales y comunidades mapuche en isépiChile. Aportes para la reconstrucción etnográfica del desarrollo interétnicos. Polis, 11:31, 355-371. Universidad de los Lagos, Santiago, Chile.

Cisternas, M., Martínez, P., Oyarzún, C. y Debels, P. (1999). Caracterización del proceso de reemplazo de vegetación nativa por plantaciones forestales en una cuenca lacustre de la Cordillera de Nahuelbuta, VIII Región, Chile. Revista Chilena de Historia Natural, 72 Santiago, Chile.

Claude, M. (1999). Las miserias del modelo chileno (una mirada desde la sustentabilidad). En Drake P. y Jacksic, I (Ed.). El modelo chileno. Democracia y desarrollo en los noventa. LOM, Santiago, Chile.

Delamaza, G. (2012). Responsabilidad social empresarial, política e internacionalización. El caso del «conflicto de los cisnes» en Valdivia. Apuntes, 39:70, 167-202Valdivia, Chile.

De Matheus e Silva, L. (2016). Desposeer para acumular: reflexiones sobre las contradicciones del proceso de modernización neoliberal de la agricultura chilena. Mundo Agrario, 17:34. Universidad de la Plata, Argentina

Dematteis y Governa, (2005) Territorialità, Sviluppo Locale, Sostenibilità: il modelo SLoT. Milano: Franco Angeli

Farris, (2013). Desarrollo rural en tiempos de globalización. Análisis de las políticas públicas en su aplicación a estudio de casos (España e Italia). Tesis de Doctorado defendida el 19/04/2013 por la Universidad Complutense Madrid

Farris, M. (2012). Valorización del patrimonio endógeno rural:" buenas prácticas" del GAL Terre Shardana (Italia). En Investigando en rural, 605-614, Ed. Ulzama. 
Farris, M. (2008). Relaciones multi-escalares, políticas públicas y desarrollo local rural. Un acercamiento teórico desde una perspectiva mediterránea. Actas XI Coloquio Ibérico de Geografía. (ISBN: 978-84-8138792-6), Alcalá de Henares, España.

Fawaz, J. (2000). Expansión forestal en Nuble y reestructuración social y productiva a nivel local. Percepción de los actores. Tiempo y Espacio, 8, Chillán, Chile.

Fazio, H. (2005). Mapa de la extrema riqueza al año 2005. Lom, Santiago, Chile.

Folchi, M. (2001). Conflictos de contenido ambiental y ecologismo de los pobres: no siempre pobres, ni siempre ecologistas. Ecología Política, 22

Foucault, M. (2008). Seguridad, territorio, población. Madrid: Akal.

Fuentes, C. (2012). El pacto. Poder, Constitución y prácticas políticas en Chile (1990-2000). Ediciones UDP, Santiago, Chile.

González, S. (2005). La geografía escalar del capitalismo actual. Geo Crítica / Scripta Nova. Revista electrónica de geografía y ciencias sociales IX: 189. Universidad de Barcelona, Barcelona, España.

Gorenstein, S. (2015). Transformaciones territoriales contemporáneas. Desafíos del pensamiento latinoamericano. EURE, 41:122, Santiago, Chile.

Governa, F. (2007). Territorialità e azione collettiva. Una riflessione critica sulle teorie e le pratiche di sviluppo locale. Rivista Geografica Italiana, 114, 335-361, Roma, Italia

Gutierrez Puebla, J. (2001). Escalas espaciales, escalas temporales. Estudios geográficos, 62:242, 89-104, Madrid, España.

Hartwig, F. (1999). Federico Albert, pionero del desarrollo forestal en Chile:: Editorial Universidad de Talca, Talca, Chile.

Hernández, R. y Pezo, L. (2010). La Ruralidad Chilena Actual. Aproximaciones desde la Antropología. Colibris, Santiago, Chile

Joignant, A. (2012). La razón de estado: usos políticos del saber y gobierno científico de los technopols en Chile (1990-1994). En Ariztía, T. (Ed.). Produciendo lo social. Usos de las ciencias sociales en el Chile presente. Ediciones UDP, Santiago, Chile.

Klubock, T. (2011). El trabajo de la naturaleza y la naturaleza del trabajo: historia medioambiental como historia social. En Cordero, R. (Ed.). Formas de comprender el presente, 52-80, Ediciones UDP, Santiago, Chile.

Klubock, T. (2014). La Frontera. Forest and Ecological Conflict in Chile's Frontier Territory. Duke University Press.

Magnaghi, A. (2000). Il progetto locale. Bollati Boringhieri, Milano, Italia

Markoff, J. y Montecinos, V. (2012). Del poder de las ideas económicas al poder de los economistas.

En T. Ariztía, (Ed.). Produciendo lo social. Usos de las ciencias sociales en el Chile presente. Ediciones UDP, Santiago, Chile.

Martínez-Alier, J. (2004). El ecologismo de los pobres. Conflictos ambientales y lenguaje de valoración. Icaria, Barcelona, España.

Meller, P. (1996). Un siglo de economía política chilena (1890-1990). Chile: Editorial Andrés Bello.

Ministerio de Agricultura (28 octubre 1974) Decreto Ley 701: FIJA REGIMEN LEGAL DE LOS TERRENOS FORESTALES O PREFERENTEMENTE APTOS PARA LA FORESTACION, Y ESTABLECE NORMAS DE FOMENTO SOBRE LA MATERLA

Molina Ibáñez, M. y Farris, M. (2012). Desarrollo rural y políticas públicas: un análisis multiescalar. Geographicalia 59-60. Zaragoza, España

Molina Ibáñez, M. (2005). Hacia un equilibrio territorial en la España del siglo XXI: los retos del desarrollo rural. Cuenta y razón del pensamiento actual, 91-106. Fundación de Estudios Sociológicos, Madrid, España

Montalba, R. y Carrasco, N. (2003). Modelo forestal chileno y conflicto mapuche: ¿ecologismo cultural? Ecología Politica, 26, 63-69

Mouffe, C. (2014) Agonística. Fondo de la Cultura Económica, Buenos Aires, Argentina. 
Peck, J. (2010). Economías políticas de la escala: políticas rápidas, relaciones inter desarrollo regional. Desafíos para América Latina. Miño y Davila, Buenos Aires, Argentina.

Pezo, L. (2007). Construcción del desarrollo rural en Chile: apuntes para abordar el tema desde una perspectiva de la sociedad civil. Revista Mad, 17, 90-112

Raczynski, D. (1999). Políticas sociales en los años noventa en Chile. Balance y desafíos. En P. Drake y Jacksic, I. (Ed.). El modelo chileno. Democracia y desarrollo en los noventa. Chile: LOM, Santiago, Chile.

Román, Á. y Barton, J. (2015). Una ecología política de las transformaciones territoriales en Chile: poder y gobernanza en los sectores forestal y salmonero. En Barton, J., Bustos, B. y Prieto, M. (Eds.), Ecología política en Chile. Naturaleza, propiedad, conocimiento y poder, 237-264. Editorial Universitaria, Santiago, Chile.

Sevilla, Á. (2014). Hegemonía, gubernamentalidad, territorio. Apuntes metodológicos para una historia social de la planificación. Empiria, 27, 49-72.

Silva, P. (2010). En el nombre de la razón. Tecnócratas y política en Chile. Ediciones UDP, Santiago, Chile.

Silva, P. (2012). Tecnócratas y política en Chile: de los Chicago Boys a los Monjes del Cieplan. En T. Ariztía, (Ed.). Produciendo lo social. Usos de las ciencias sociales en el Chile presente. Ediciones UDP, Santiago, Chile.

Undurraga, T. (2014) Rearticulación de grupos económicos y renovación ideológica del empresariado en Chile 1975-2012: la paradoja de la concentración. En Monsalve Zanatti, M. Grupos Económicos y Mediana Empresa Familiar en América Latina, Universidad del Pacífico, Lima, Perú

\section{Fuentes digitales}

AntarChile, (2018). www.antarchile.cl

CIREN (2010) Determinación de la erosión actual y potencial de los suelos de Chile http://www.corma.cl/_file/material/determinacion-de-la-erosion-actual-y-potencial-de-los-suelos-dechile-ciren-2010.pdf

CORMA (2012). Memoria 2011/2012. Santiago, Chile. Recuperado en: http://www.corma.cl/biblioteca-digital

CORMA (2015) El agua y las plantaciones forestales. Aporte al conocimiento de la gestión sustentable En: http:/ / www.corma.cl/biblioteca-digital/publicaciones-y-estudios

CORMA (2016) Las Plantaciones Forestales. Un Aporte a la Recuperación de Suelos Degradados en Chile. En: http://www.corma.cl/biblioteca-digital/publicaciones-y-estudios

CONAF (2017) Estadísticas forestales Recuperado en: http://www.conaf.cl/nuestros-bosques/bosquesen-chile/estadisticas-forestales/

CONAF (2017) Plantaciones forestales 1998 al 2015 por comuna. Recuperado en:

http://www.conaf.cl/nuestros-bosques/bosques-en-chile/estadisticas-forestales/

CONAF, (2017), www.sit.conaf.cl

El Mercurio (29 agosto 2007) La historia del inmigrante italiano que llegó a ser el más rico de Chile.

Recuperado en:

http:/ / diario.elmercurio.com/detalle/index.asp?id=\%7Bb8ed7285-0c6e-4072-83d2-

4249ea8e9905\%7D

Empresas Copec, (2018), www.empresascopec.cl

EMPRESAS COPEC (2016) Memoria anual 2015.

González, S. (2005). La geografía escalar del capitalismo actual. Geo Crítica / Scripta Nova. Revista electrónica de geografía y ciencias sociales vol. IX, n. 189. Barcelona: Universidad de Barcelona

Gutiérrez, M. (2017) Arauco negocia compra en Brasil que la llevaría al 1 lugar en celulosa. Economía y Negocios (17 junio 2017). Recuperado en:

http://www.economiaynegocios.cl/noticias/noticias.asp?id=370654

INFOR (2017) Anuario forestal 2017. Santiago, Chile. 
INFOR (2015) La industria forestal primaria en Chile. Santiago, Chile.

Innovar Chile (2016) Estudio fuerza laboral de la industria forestal chilena 2015-2030. http:/ /www.corma.cl/file/ material/ estudio-fuerza-laboral-de-la-industria-forestal-chilena-2015-

2030.pdf

Matamala, D. (09/12/2015) Los dueños de Chile, CIPER en

http:/ / ciperchile.cl/2015/12/09/los-duenos-de-chile/

PNUD (2004) Las trayectorias del desarrollo humano en las comunas de Chile (1993- 2003) http://desarrollohumano.cl/idh/download/IDHC\%20con\%20portada.pdf

PROGEA (2015) Aporte económico y social del sector forestal en Chile y análisis de encadenamiento. http://www.corma.cl/_file/material/aporte-economico-y-social-del-sector-forestal-en-chile-y-analisisde-encadenamiento.pdf

Pulso (19 diciembre 2017) Tras compra en Brasil, Arauco adquiere activos de MASISA en Mexico por US $\$ 245$ millones. Recuperado en: http://www.pulso.cl/empresas-mercados/tras-compra-brasil-araucoadquiere-activos-masisa-mexico

PWC (2016) Global Forest, Paper \&Packaging Industry survey. Recuperado en: https://www.pwc.com/gx/en/industries/assets/pwc-annual-fpp-industry-survey-2016-10.pdf

Saleh, F. (2011) La estrategia de Tironi para levantar imagen de Arauco después del terremoto (22 marzo 2011) El Mostrador Recuperado en:

http://www.elmostrador.cl/noticias/pais/2011/03/22/la-estrategia-de-tironi-para-levantar-imagende-arauco-despues-del-terremoto/

Zonas Rezagadas. http://www.zonasrezagadas.subdere.gov.cl/ 